\title{
Sharing Health Risk Messages on Social Media: Effects of Fear Appeal Message and Image Promotion
}

\author{
Xueying Zhang ${ }^{1}$, \& Shuhua Zhou ${ }^{2}$ \\ ${ }^{1}$ North Carolina Agricultural and Technical State University, Greensboro, North Carolina, USA \\ 2 University of Missouri, Columbia, Missouri, USA
}

\begin{abstract}
This study examined how fear appeal and individuals' image promotion consideration drive users' intention to share fear appeal messages on social networking sites (SNS). A mixed factorial experiment [2 (high vs. low threat) $\times 2$ (high vs. low efficacy) $\times 2$ (topic)] was conducted online with a sample of 214 participants recruited from United States. Process regression analysis results indicated that (1) high threat message elicited significant higher intention to share fear appeal messages on SNS; (2) fear arousal significantly enhanced intention to share risk messages directly; (3) high efficacy message resulted in higher intention to share fear appeal messages on SNS through the moderated mediated effect of information processing and intention to follow the health advice; and (4) individual's intention to promote image on SNS was positively related to intention to share. Theoretical and practical implications for health risk communication on SNS are discussed.
\end{abstract}

Keywords: SNS; intention to share; health risk message; fear appeal; persuasion; image management

\section{Introduction}

The dissemination of health risk information is a topic of key importance in health communication. At the individual level, exposure to health information allows individuals to recognize and exert control over health-related events in action (Jacobs et al., 2017). Collectively, effective health information dissemination promotes health literacy enhancing health conditions and reducing the rates of hospitalizations and mortality (Cameron et al., 2011).

Over the last two decades, social networking sites (SNS) have become important online destinations. Through a network of users and with a culture of sharing, SNS have shown great potential for disseminating information (Oh \& Syn, 2015). Health promotion professionals have been quick to acknowledge the power of social media, such as Facebook, for reaching and informing broad audiences, as well as empowering them in health-related activities (Thackeray et al., 2008). The Centers for Disease Control and Prevention (CDC) even issued its Facebook guidelines, "participation on Facebook and other social media tools are intended to be part of a larger integrated health communications program" (CDC, 2015). However, SNS users can also impede potentially beneficial information sharing by selectively filtering out information, thus, limiting exposure to themselves only (Zhang \& Zhou, 2019). As the power of gatekeeping shifts to individual users, "share" functions as a critical component for information dissemination on social media.

For decades, fear appeal studies have tested the main and interactive effects of threat and efficacy on information processing and persuasion; however, no consistent conclusion has been reached. Effects of fear appeal message have also been observed to vary widely among different attitudinal and behavioral outcomes (e.g., de Hoog et al., 2007; Hansen et al., 2010; Tannenbaum et al., 2015). In the fear appeal literature, the examination of intention to share information as a result of exposure has been largely neglected (Rimal \& Real, 2003). However, in the social media age, 
this neglect is no longer trivial, as exposure is dependent on sharing. In addition, if we conceptualize intention to share risk messages as a form of self-protective behavior (Rimal \& Real, 2003), its significance is even more pronounced. On the other hand, uses and gratifications theory suggests individuals use media to actively seek gratifications of their needs (Katz, 1959; Rubin, 2009). Typically, posting message may serve an image promotional purpose in addition to spreading protective information. All these open up potential grounds for investigation.

Employing an experimental design and from a user's perspective, this study examines content variables including threat and efficacy and user variables including processing style and image promotional consideration to investigate the combined influence in driving SNS users' intention to share fear appeal messages. It is hoped that the results provide insights that can help health communicators to better understand the nature of fear appeal messages' dissemination on social media, hence, empower them in effective message designs.

\section{SNS in Health Communication}

Under the big umbrella of social media, there are many specialized platforms targeting different users and fulfilling a variety of purposes, such as text messaging, photo sharing, wikis, weblogs and discussion forums (Harris \& Rea, 2009). Roughly speaking, these applications serve two major functions. Sites such as YouTube, Wikis are mainly for collaborative content development, while sites such as Facebook, Twitter, Linkedln and MySpace are recognized as social networking services (SNS) (Korda \& Itani, 2013). While content creation mainly serves informational purposes, SNS are used to manage identities, and building communities. (Adzharuddin \& Ramly, 2015).

An intensively studied and most pervasively used SNS is Facebook. Initially founded in 2004 by Mark Zuckerberg, Facebook is first used by Harvard students and then other college students around U.S. campuses. In 2006, it opened up to the public and experienced explosive growth in the following decade. By the end of year 2019, Facebook serves 2.37 billion monthly active users (Hutchinson, 2019). After registration, users of Facebook can create profiles, add other users as friends, and post status updates. Friends get notifications when one updates his/her profile unless the person is particularly blocked. On Facebook, users could "like" certain "pages" and get access to an individual's or an organization's status updates. As such, Facebook users are exposed to content on the newsfeed depending on who they choose to connect as friends and what organizations they subscribe to. They could potentially re-share messages that they see. In summary, Facebook, like other social networking sites, provides a mechanism for potential message receivers to create, share and seek content, as well as to interact and collaborate with each other (Lee \& Ma, 2012). The networking function of SNS facilitates information dissemination by allowing users to create and maintain connections with those who have similar needs, interests or problems (Cho et al., 2010).

Health promotion professionals have been quick to acknowledge the power of SNS such as Facebook for reaching and informing broad audiences, as well as empowering them in health -related activities (Thackeray et al., 2008). Several advantages have been recognized for Facebook to be used in the effort to communicate health issues. First, it is inexpensive for health professionals to reach large and targeted audience. Woolley and Perterson's (2012) study on Facebook, for instance, notes that it can be used in maintaining and promoting healthy lifestyle either by motivating and reminding the users to engage in healthy behaviors, or by instructing users to prepare and take action.

Attention to health information is not only paid to expert sources, but also to peers in one's network. Qualitative studies have indicated that sharing health information on SNS such as Facebook might be a way for people to start conversations with social peers, while creating possible opportunity toward finding other people with shared health issues (Torabi \& Beznosov, 2013). A related point is that as communities can be formed easily on SNS, a channel for social support is provided, creating a sense of connectedness (Korda \& Itani, 2013). Through a network of users and a culture of share, SNS shows great potential value for disseminating information, making it an important online platform for health care professionals (Scanfeld et al., 2010).

\section{The Evolvement of Fear Appeal Study}

A great proportion of health information is risk related and is especially concerning to the public. For decades, fear appeal effects studies have examined the effectiveness of using threatening message to "promote precautionary motivation and self-protective action" (Ruiter, Kok et al., 2001, p. 614). A fear appeal message persuades by arousing fear, an unpleasant emotion, and that fear must be associated with the perception of threatening stimuli (Ruiter, Kok et al., 2001). 
The theoretical study of fear appeal message starts as early as the 1950s, guided by the drive-reduction model (Hovland et al., 1953; Janis, 1967; McGuire, 1968, 1969), focusing on motivational drives including attitudes, goals, needs, and emotional arousal (Ruiter, Abraham et al., 2001) in explaining the persuasiveness of fear appeal messages. The drivereduction model posits a curvilinear relationship between levels of fear and persuasion, suggesting a moderate level of fear lead to maximum persuasion (Janis, 1967; McGuire, 1968, 1969). Following this model, Leventhal's (1970, 1971) Parallel Response Model (PRM) and the Protection Motivation Theory (PMT) (Rogers, 1983) shift attention on emotional arousal to the cognitive elaboration of fear appeal messages. Specifically, PMT (Rogers, 1983) specifies that cognitive appraisal of fear appeal messages usually results in evaluation of that a hazard's severity and susceptibility outweighs the consequences associated with maladaptive behaviors, and that coping appraisal assesses levels of response efficacy, self-efficacy, and the costs of those behaviors. The two appraisals interact in generating "intention to adopt the communicator's recommendation" (Rogers, 1983, p. 158). Witte (1992), however, criticizes Leventhal's (1970) PRM and Rogers' (1983) PMT's exclusive cognitive approach and proposes an extended parallel process model (EPPM) to consider both cognitive and emotional process of fear appeal messages.

Based on voluminous studies testing these fear appeal perspectives over the last few decades, meta-analysis studies suggest that the role and interactions of threat and efficacy in this process is still not fully understood (Ruiter, Kok et al., 2001; Tannenbaum et al., 2015). There is no consistent conclusion regarding what types of message features cause a particular effect. For example, studies using PMT find relatively strong and consistent main effects for response efficacy and self-efficacy on intention for action, but they don't not always detect such effect with perceived susceptibility and perceived severity (Bandura, 1996; Eagly \& Chaiken, 1993; Floyd et al., 2000; Milne et al., 2000). But this much is clear: fear appeal studies collectively suggest main effects of threat and efficacy, while interaction effect of threat and efficacy is less definite (de Hoog et al., 2007; Witte \& Allen, 2000; Tannenbaum et al., 2015). Second, fear appeal effects research also shows conflicting results regarding various outcome variables. For example, de Hoog et al. (2007) find that attitude is more likely to be influenced by threat severity and argument quality, but not necessarily for outcomes such behaviors and intentions. This suggests that such message effects involve a rather complicated mechanism between both IVs and DVs. Added to this imperfect picture is the fact that studies on sharing on SNS as a result of exposure to a fear appeal messages have been infrequent. By adding "share" as a key variable in the context of social media, we can enrich this body of literature.

\section{Influence of Threat and Efficacy on Intent to Share Health Fear Appeal Messages on SNS}

In addition to conceptualizing sharing intention as a key, we also propose hypotheses regarding the influence of threat and efficacy messages based on the concept of informational utility (Knobloch et al., 2003; Knobloch-Westerwick et al., 2005; Knobloch-Westerwick et al., 2015), which is originally proposed to explain selective exposure to news messages. Knobloch and colleagues (2003) conceptualize that informational utility, referring to information users' perception about how much supplied information would assist them in establishing reliable orientations and adapting to environments. Specifically, Knobloch et al. (2003) operationalize the concept of "information utilities" as having three dimensions: magnitude of challenges or gratifications, perceived likelihood of their materialization, and perceived immediacy or proximity in time of materialization. Later perceived efficacy to influence external stimuli is also added (KnoblochWesterwick et al., 2005). As can be seen, these informational utility dimensions largely correspond to perceived threats (including perceived severity and perceived susceptibility) and perceived efficacy as examined in fear appeal studies. So far, multiple studies have generated empirical evidence supporting informational utility as a predictor of selective exposure to news story about disasters (Knobloch et al., 2003), radio news (Dillman Carpentier, 2008) and political messages (Knobloch-Westerwick \& Kleinman, 2012).

Applying the same logic to sharing health-related information online, people may share health advice that they personally find useful and of benefit to a larger audience, a proposition that has been empirically supported with a sample of Twitter users (De Choudhury et al., 2014). According to Berger and Milkman (2012), perhaps the most important reason for people to share any information online is because they cognitively recognize the usefulness of the information. This is manifested when consumers share coupons or information about good restaurants (Wojnicki \& Godes, 2008), and tourists share their travel experience (Munar \& Ooi, 2012). When it comes to fear appeal messages, if the perceived usefulness of a message can be measured with perceived threat and perceived efficacy as proposed in the concept of informational utility (Knobloch-Westerwick et al., 2005; Knobloch-Westerwick et al., 2015), elevated perceptions of threat and efficacy may therefore lead to increased intention to share the risk message on social media.

Therefore, the current study proposes: 
$\mathrm{H} 1$ : A high threat message elicits higher intention to share on social media as compared to a low threat message.

H2: A high efficacy message elicits higher intention to share on social media as compared to a low efficacy message.

\section{Influence of Fear on Intent to Share Health Fear Appeal Message on SNS}

Next, the current study proposes significant impact of fear in driving intention to share fear appeal message on SNS (Hovland et al., 1953; Janis, 1967; McGuire, 1968, 1969). Witte (1992)'s EPPM proposes that fear can serve as either a motivator for considering coping recommendations when perceived efficacy is high or as a reason to avoid risk message and to deny the threat when perceived efficacy is low. More direct evidence for hypothesizing the role of fear in driving intention to share fear appeal message can be found from analyses of online content and studies of rumor dissemination. For example, Stieglitz and colleagues (Stieglitz \& Dang-Xuan, 2013) observe that emotionally charged messages are more often and more quickly retweeted than neutral messages, because of the emotional potential in eliciting arousal in audiences (Berger, 2011; Berger \& Milkman, 2012; Stieglitz \& Dang-Xuan, 2013). Different kinds of emotion-related content have different impacts on sharing rate, with content that elicits highly arousing emotions such as awe, amusement, anger, and anxiety found to be more viral than low arousing emotions. Studies of rumor dissemination also recognize fear and anxiety as key motivators for spreading on two grounds: first, fear serves as a signal of importance (Oh et al., 2010). Second, fearful people are found to have a greater need for sharing to release emotional pressure and rationalize ambiguous information (Allport \& Postman, 1947). The role of fear in driving rumor dissemination has received empirical evidence from laboratory studies (e.g., Berger \& Milkman, 2012; Luminet et al., 2000). Luminet et al. (2000), for example, find that participants who experienced intense emotions consistently display significantly higher levels of social sharing than participants in moderate- and non-emotional conditions. Based on the above discussion of fear and share, the following hypothesis is proposed:

H3: Fear is positively related to users' intention to share on social media.

\section{A Moderated Mediation Path: Influence of Information Processing and Intention to Follow the Advice}

The current study also examines the potential of information processing mode in moderating the relationship between social media users' cognitive or affective elaboration and sharing intention. According to dual-processing theories, such as ELM (Petty \& Cacioppo, 1986) and HSM (Chaiken et al., 1989), individuals vary their effort in processing information. People who process information via peripheral route, or heuristically process information typically rely on simple decision rules such as information source, while people who adopt the central route, or process information systematically, typically evaluate the message carefully by weighing arguments and relating them to information already held.

In health information processing, style is related to judgement of risk. Trumbo (2002) and Lopes (1991) observe an association of heuristic processing with low judged risk and systematic processing with high judged risk. The staged model of fear appeal message effect posits that if individuals form a perception of high susceptibility and severity of the threat, they would more likely engage in systematic processing of recommendation messages to be reassured (de Hoog et al., 2008). Similarly, the feeling of anxiety or worry is suggested to be a motivator for systematic processing because anxiety lowers individuals' judgmental confidence of their current knowledge being sufficient for decision making (Griffin et al., 1999). Gleicher and Petty's (1992) suggest that fear arousal, coupled with the expectation for reassurance, elicits systematic processing of both threat and coping message.

While information processing can be viewed and tested as a reaction to a specific message, previous scholars also note that the information processing strategies individuals apply to a specific message tend to be "a manifestation of the strategies that they apply more generally when they encounter risk information in the mass media or elsewhere" (Kahlor et al., 2003, p. 363). While threat and fear have the potential to drive systematic processing, a range of other factors also contribute in influencing information processing strategies, such as individual's involvement with the situation, ability to engage with systematic processing (Petty \& Cacioppo, 1986; Chaiken et al., 1989), sufficiency of information, (Griffin et al., 1999), and prior knowledge (Averbeck et al., 2011). As Yang et al. (2014) pointed out, it combines social, psychological and communication factors to predict individuals' information processing styles. Therefore, instead of focusing on why individuals process fear appeal message systematically or heuristically, the current study aims to examine how individuals form intention to share the fear appeal message on SNS after processing has been made, as processing information is a critical step that individuals go through before they form an attitude. 
The current study hypothesizes the effort of information processing moderates the influence of threat, efficacy and fear on intention to follow the advice contained in a fear appeal message, which then leads to intention to share the message on SNS. Some scholars suggest sharing online cultivates an altruistic and cooperative online community culture (Hsu et al., 2007). Others view sharing as driven by innate self-centered motivations, such as gaining respect and recognition, increasing social ties, augmenting self-esteem, engaging in community activities, and enhancing reciprocal exchange (Baym, 2010; Gretzel \& Yoo, 2008). Given these, sharing a message that an individual personally believes in and intends to try on him/herself should be more likely to be perceived as helpful to fulfill the above-mentioned motives. This rationale is confirmed in a survey study examining Twitter users' motivations for sharing health information, as the most frequently reported reason was to help others to benefit from health information they personally had found useful (De Choudhury et al., 2014). As such, we propose that when fear is working, when a threat motivates action, and when a message offers efficacy to the extent that the user intends to follow health advice, that the user is more likely to share such a message because it is perceived to be beneficial to others.

RQ1a: Does information processing moderate threat in influencing intention to follow the adviced message?

H4a: Intention to follow the advice mediates the moderated effect of threat by information processing on users' intention to share fear appeal messages on SNS

RQ1b: Does information processing moderate efficacy in influencing intention to follow the adviced message?

H4b: Intention to follow the advice mediates the moderated effect of efficacy by information processing and users' intention to share fear appeal messages on SNS

RQ1c: Does information processing moderate fear in influencing intention to follow the adviced message?

H4c: Intention to follow the advice mediates the moderated effect of fear by information processing on users' intention to share fear appeal messages on SNS

\section{Willingness to Create a Positive Image on SNS}

One concern of sharing information on social media is users' image promotional consideration. Uses and gratifications theory assumes individuals are goal-directed in meeting their needs when using media (Katz, 1959; Rubin, 2009). Depending on the type of content, sharing behaviors on SNS have been correlated with information seeking, socializing, entertainment, status seeking, attention seeking, and habitual past time, etc. (e.g., Lee \& Ma, 2012; Malik et al., 2015). Although SNS users are motivated to share in order to seek a variety of gratifications, they usually keep an imagined audience in mind and adapt their presentation strategies accordingly (Marwick, 2011). The imagined audience might be entirely different from actual readers, yet it imposes social norms on sharing and raises privacy concerns on SNS users (Marwick, 2011). Impression management is a major concern when users interact with others on social media, especially for health purposes. It is reported that people are more likely to present positive health status on the self on social media and avoid negative ones (Newman et al., 2011). However, impression management concern does not necessarily lead to complete self-censorship, because people use SNS to communicate and through which to cultivate and leverage social capitals (Ellison et al., 2007). Users just have to balance the conflicts between the desire of self-expression, intimate connections, and impression management concern.

Compared with face-to-face communication, SNS users have more control over self-presentation and are able to manage impression more precisely (Krämer \& Winter, 2008). Most pervasively, users take advantage of such control to selfpromote themselves. Literature on image management has frequently related self-presentation with personality characteristics such as narcissism (e.g., Turel \& Gil-Or, 2019) and self-esteem (e.g., Gonzales \& Hancock, 2011; Krämer \& Winter, 2008; Valkenburg et al., 2005). SNS indeed may encourage such behaviors since posting self-promoting content, such as photos, wall posts and status updates could help garner attention from others, express their identity, and reinforce their self-concept (Gentile et al., 2012). Positive self-presentation also helps improve self-esteem as users present socially desirable images and the reflection of the polished version of oneself is self-enhancing (Gonzales $\&$ Hancock, 2011). Therefore, more often than not, SNS activity is motivated by individuals' need for self-enhancement and to appear more likeable (Lee et al., 2012). In light of the above discussion, the current study proposes: 
H5: Willingness to create a positive image of oneself on Facebook positively predicts intention to share the fear appeal message.

The conceptual model thus takes all these hypotheses and research in mind, and is demonstrated by Figure 1 .

Figure 1. Conceptual Model Predicting Intention to Share Fear Appeal Health Message on Social Media.

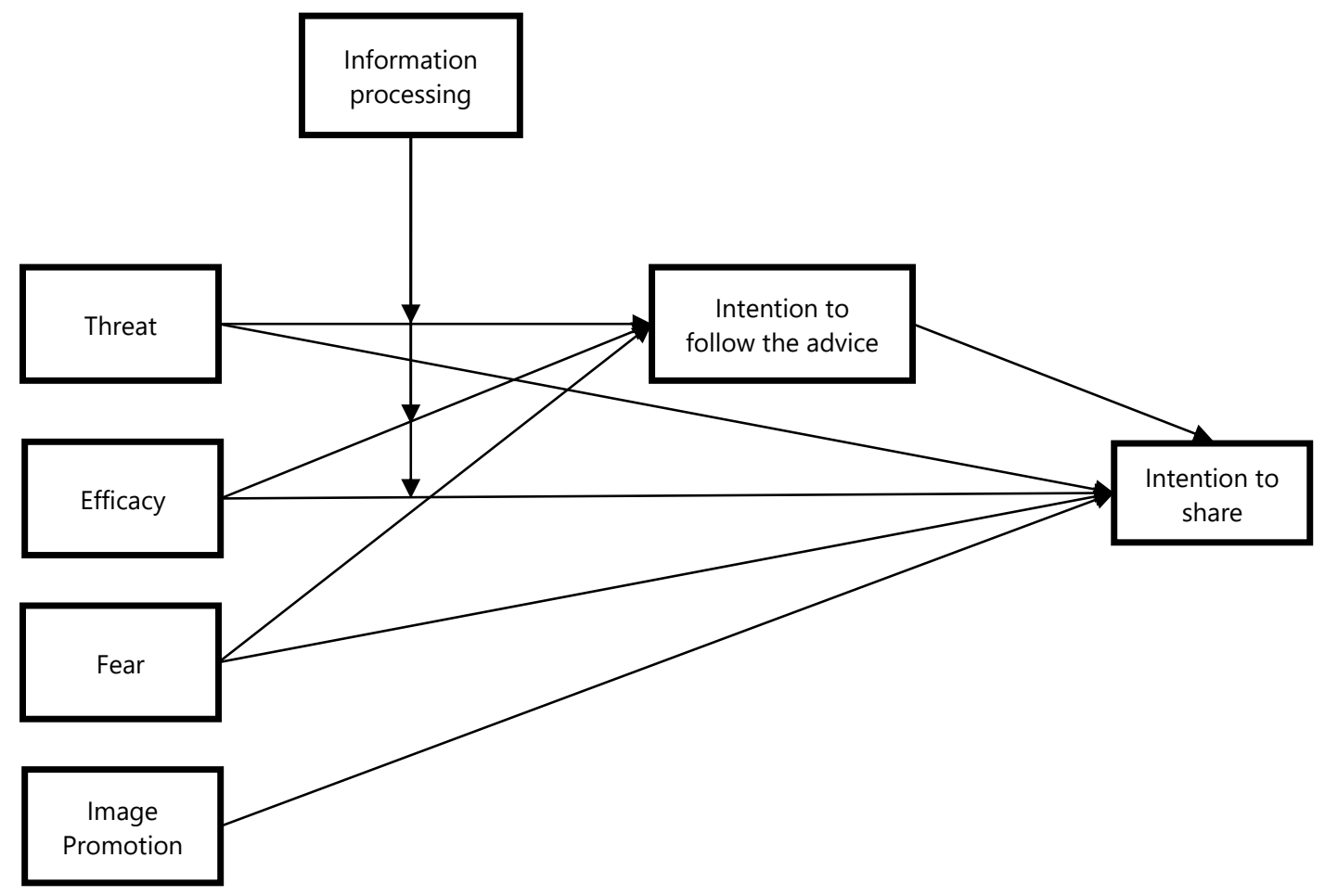

Method

A mixed factorial experimental design was used to test message feature's effects on users' intention to share risk message on social media. Two messages feature, namely level of threat and level of efficacy were manipulated as between-subject factors. Two fear appeal messages were selected as a within subject factor to guard against single message effects (O'Keefe, 2015). As such, the experiment was a 2 (fear appeal topic) $\times 2$ design (high vs. low threat) $\times 2$ (high vs. low efficacy) mixed design, with data collected for each topic in random order. Facebook was chosen as the hypothetical context in data collection, as it is one of the most popular social media sites (Greenwood et al. 2016).

\section{Stimuli Design and Manipulation Check}

The two fear appeal topics, used to guard against single message effects (O'Keefe, 2015), included listeriosis infection and digital eyestrain that could affect everyone in the population. For each topic, four articles of around 200 words were created with manipulated threat and efficacy messages. The threat message was manipulated by varying the use of statistics and adjectives to emphasize the high/low rates of occurrence for the risk and symptoms of different level of severity. Graphic photos of a person suffering listeriosis infection and digital eyes train were used to illustrate the high threat message, whereas pictures showing a plate of vegetable salad and digital screen were used to convey low threat. Efficacy was manipulated by either providing or not providing information regarding easy-to-implement prevention methods and confirmed effectiveness of prevention tips, and attributing the risk factors to elements either within the control or not of individuals. Messages were presented in the form of a mock Facebook post, with the source being set as CDC (Center for Disease Control and Prevention) to control for potential confounding influence of source credibility.

Several rounds of pretests were conducted with student samples recruited from a Southeast public university in the United States. Students were presented with the stimuli and then they completed a manipulation questionnaire testing perceived threat and perceived efficacy. The stimuli revision continued until the results showed significant differences both between high threat group ( $M=4.89$ (on a 7 point scale), $S D=1.09, N=30$ ) and low threat group $(M=4.03$, $S D=1.34, N=23, t=2.12, p<.05$, Cohen's $d=.64)$, and between the high efficacy group $(M=5.56, S D=1.33, N=27)$ 
and low efficacy group $(M=4.65, S D=1.68, N=26, t=5.58, p<.01)$. Further, the perceived threat and efficacy were not observed to differ significantly between the two health topics.

\section{Sampling and Procedures}

Participants were recruited on Amazon Turk (www.MTurk.com) between January $11^{\text {th }}$ to February $5^{\text {th }}$, 2017. Participants were filtered by two questions, (1) Are you a Facebook user? and (2) Are you 20 years or older? If they indicated yes, they were led to the Qualtrics online experiment where they first read a consent form. After that participants were randomly assigned to one of four experimental conditions and exposed to two fear appeal messages in random order. Then they filled out a questionnaire measuring variables of interests. To filter out those who took the survey without actually reading the message, an attention check question testing the comprehension of the message was placed after the questionnaire items and before demographic questions. An embedded timer on Qualtrics was also used to eliminate those who spent less than 300 seconds taking the survey. Each participant was paid one dollar (USD) for participation.

Before recruiting participants, a power analysis was conducted to determine the desired sample size, using the G*Power 3.1.9.2. statistical software for an ANCOVA (Faul et al., 2007). The test was performed using a specified power of .95, significance level of .05 , and medium effect size $(f=.25)$, given that Cohen (1992) suggested that as long as the effect size is not small enough to become trivial, a medium effect size represented an effect likely visible to a careful observer. 4 groups were included in the power analysis, involving 4 between-subject conditions and two covariate variables. The power analysis showed that a total sample of $210(N=210)$ was sufficient.

The study recruited 275 participants from MTurk, of whom 262 proceeded to participate after reading the consent form. Of those, 23 were eliminated for failing the attention check, and 25 others for spending fewer than 300 seconds, resulting in a final sample of 214 participants. Participants' demographic information was documented in Table 1.

Table 1. Demographic Information of the Sample $(N=214)$.

\begin{tabular}{|c|c|c|c|c|}
\hline Gender & Ethnicity & Education & Facebook use & Health status \\
\hline Male (38.3\%) & $\begin{array}{c}\text { African American } \\
(8.8 \%)\end{array}$ & $\begin{array}{l}\text { High school diploma } \\
(24.8 \%)\end{array}$ & $\begin{array}{l}\text { Less than } 10 \text { min. } \\
(19.2 \%)\end{array}$ & $\begin{array}{l}\text { Needs a great deal of } \\
\text { improving }(5.1 \%)\end{array}$ \\
\hline \multirow[t]{5}{*}{ Female (61.2\%) } & Asian (5.6\%) & $\begin{array}{c}\text { Associate degree } \\
(17.8 \%)\end{array}$ & $10-30 \min .(33.2 \%)$ & $\begin{array}{c}\text { Needs some improving } \\
(18.7 \%)\end{array}$ \\
\hline & Hispanic (4.7\%) & $\begin{array}{l}\text { Undergraduate } \\
\text { degree }(41.6 \%)\end{array}$ & $\begin{array}{c}\text { More than } 30 \mathrm{~min} . \text { up } \\
\text { to } 1 \mathrm{hr} .(20.1 \%)\end{array}$ & $\begin{array}{l}\text { Good but needs a few } \\
\text { improvement }(38.3 \%)\end{array}$ \\
\hline & $\begin{array}{c}\text { Native American } \\
(1.9 \%)\end{array}$ & $\begin{array}{c}\text { Master's degree } \\
\text { (12.1\%) }\end{array}$ & $\begin{array}{c}\text { More than } 1 \mathrm{hr} \text {, up to } 2 \\
\text { hrs }(14.5 \%)\end{array}$ & Very good (33.6\%) \\
\hline & $\begin{array}{c}\text { White/Caucasian } \\
\text { (78\%) }\end{array}$ & $\begin{array}{c}\text { Doctorate degree } \\
(2.3 \%)\end{array}$ & $\begin{array}{c}\text { More than } 2 \mathrm{hrs} \text {, up to } \\
3 \mathrm{hrs} .(7.5 \%)\end{array}$ & $\begin{array}{l}\text { Optimal and needs no } \\
\text { improvements (3.3\%) }\end{array}$ \\
\hline & Other $(.9 \%)$ & Other (1.4\%) & More than 3hr. (5.6\%) & \\
\hline
\end{tabular}

\section{Measurement}

\section{Perceived Threat}

The scale for perceived threat was adapted from Witte's (1992) The Risk Behavior Diagnosis Scale (RBD), which is a 12item, 7-point Likert-type scale, ranging from 1 (strongly disagree) to 7 (strongly agree). Specifically, the perceived susceptibility was measured with the items "After reading the message, I feel (1) I am personally at risk for ...; (2) It is possible that I will personally get ...; and (3) I am personally susceptible to ...". (Listeria: $\alpha=.93$; Digital Eye Strain: $\alpha=$ .90). The perceived severity was measured with the items (1) "... is a serious threat to me"; (2) "... is harmful to me"; and (3) " ... is a severe threat to me" (Listeria: $\alpha=.90$; Digital Eye Strain: $\alpha=.93$ ). (Listeria: $M=3.94, S D=1.40, N=214$; Digital Eye strain: $M=4.73, S D=1.31, N=214$ ). 


\section{Perceived Efficacy}

The concept of perceived efficacy was also measured using the RBD scale. The participants were asked the degree to which they felt (1) "The message provides methods that prevents ..."; (2) "The message provides tips that works in deterring..." and (3) "The message provides methods effective in removing the threat of ...". Another three items that were used to measure self-efficacy are (1) "I am able to follow the potential recommendations to prevent against ..."; (2) "It is easy to follow to prevent against ..."; and (3) "I can follow the recommendations to prevent against...". (Listeria: $M=$ $5.40, S D=1.04, N=214, \alpha=.88$; Digital Eye strain: $M=5.44, S D=1.04, N=214, \alpha=.79$ ).

\section{Fear}

The level of evoked fear of the fear appeal message was measured through 6 mood adjectives. Participants were asked to indicate how they felt while reading the message on a 7-point scale for six mood adjectives: frightened, uncomfortable, tense, anxious, discomfort, and nausea. The adjectives and answering scale were derived from earlier research on the effects of fear appeals (e.g., Ruiter, Kok et al., 2001). (Listeria: $M=2.22, S D=1.40, N=214 ; \alpha=.94$; Digital Eye strain: $M=2.36, S D=1.46, N=214, \alpha=.95)$.

\section{Image Promotion}

The concept was measured with two original items created for this study. The participants were asked to rate on a 7point scale regarding how much they feel sharing the message will promote their image on Facebook, and sharing the message will make their Facebook friends think them positively. (Listeria: $M=3.08, S D=1.56, N=214$; Digital Eye strain: $M=3.09, S D=1.56, N=214$ ).

\section{Intention to Follow the Advice}

Participants' intention to follow the advice that was provided by two fear appeal messages was measured with three questions adapted from Rimal and Real's (2003) study. On a 7-point Likert scale, participants were asked to what extent they intended to (1) keep kitchen and environment cleaner and safer; (2) cook meat and poultry thoroughly; (3) store foods safely; (4) maintain a comfortable working distance at the computer; (5) take a 20-second break and look off into distance and (6) wear glasses that block blue light (Listeria: $M=4.43, S D=2.05, N=214$; Digital Eye strain: $M=4.68$, $S D=1.80, N=214, \alpha=.78)$.

\section{Information Processing}

The information processing style scale was borrowed from Kahlor et al. (2003). On a 7-point Likert scale, participants were asked to rate the extent of agreement from 1(strongly disagree) to 7 (strongly agree) on their information processing strategies. Particularly, systematic processing was measured with 6 items, including "I thought about what actions I myself might take based on what I read", "I found myself making connections between the story and what I've read or heard about elsewhere", "I thought about how what I had read related to other things I know", "I tried to think of the practical applications of what I read", "I thought about what actions should be taken by policy-makers based on what I read", and "I tried to relate the ideas in the story to my own life". Three items were utilized to measure heuristic processing, including "I skimmed through the story", "I didn't spend much time thinking about the story after I read it", "The story presented too many conflicting viewpoints (Kahlor et al., 2003). In data analysis, the heuristic processing score (Listeria: $\alpha=.77$; Digital Eye strain: $\alpha=.79$ ) was reverse coded then added to the systematic score (Listeria: $\alpha=.80$, Digital Eye strain: $\alpha=.82)$. After that, the mean was taken to form a single measure of information processing $(M=5.77$, $\mathrm{SD}=1.00, N=214 ; \alpha=.82$ ).

\section{Intention to Share}

The concept of intention to share was measured by two 7-point Likert scale questions asking participants' intention to repost the message to two different places: (1) on their Facebook wall and (2) to a specific Facebook friend(s) publicly. The scores of two items were added and average was taken (Listeria: $M=2.93, S D=1.96, N=214$; Digital Eye strain: $M=3.05, S D=1.91, N=214)$. 
Participants were asked how much time they spent on Facebook every day on a seven-point scale, ranging from "no time at all (1)", to "more than three hours (7)" On average, participants reported spent around 30 minutes on Facebook everyday $(M=3.71 ; S D=1.48)$.

\section{Health Status}

Participants were asked to self-report their perception of their overall health on a five-point scale, ranging from "my overall health needs a great deal of improving (1)" to "my overall health was optimal and needs no improvements (5)". On average, the reported health status fell between "My overall health is good but needs a few improvement" and "My overall health was very good). $(M=3.11 ; S D=0.93)$.

\section{Demographics}

Demographic data were collected at the end of the questionnaire. This section included questions relating to gender, age, ethnicity and education. Gender was measured as a dichotomous variable including male and female. Age was measured as a continuous variable. Participants were asked to report how old they were in the year of 2017 as a number. Ethnicity was measured by asking participants to choose a race that they feel identifies themselves among eight options including "African Americans", "Asian", "Hispanic", "Native Americans", "Pacific Islander", "White/Caucasian" or "Other". Education was measured by asking participants what the highest degree is they obtained from "high school diploma" to "doctorate degree". Household income was measured by asking participants to choose their annual household income from "\$19k or less" to "\$200k +". Participants' demographic information was documented in Table 1.

\section{Results}

The effectiveness of intended threat and efficacy inductions were assessed again using participants' ratings of perceived threat and efficacy. As shown by Table 2, a two-way ANOVA was conducted and the results indicated the difference between the high/low threat groups, as well as between the high/low efficacy groups were all significant. In addition, no inadvertent effects of threat manipulation were observed on perceived efficacy, or vice versa. The manipulations of threat and efficacy for both stimuli were effective.

Table 2. Manipulation Check (Two-way ANOVA): Perceived Threat and Perceived Efficacy by Condition and Topic.

\begin{tabular}{|c|c|c|c|c|c|c|c|c|}
\hline & \multicolumn{2}{|c|}{ Listeria } & \multirow[b]{2}{*}{$F$} & \multirow[b]{2}{*}{$p$} & \multicolumn{2}{|c|}{ Digital Eye Strain } & \multirow[b]{2}{*}{$F$} & \multirow[b]{2}{*}{$p$} \\
\hline & High & Low & & & High threat & Low threat & & \\
\hline Threat & 4.24 & 3.63 & 9.04 & .002 & 5.10 & 4.70 & 5.87 & .02 \\
\hline Efficacy & & & 1.21 & .27 & & & 0.04 & .84 \\
\hline Threat*Efficacy & & & 0.05 & .82 & & & 2.04 & .16 \\
\hline \multicolumn{5}{|c|}{$\eta^{2}=.04, r=.63$, Power $=.85$} & \multicolumn{4}{|c|}{$\eta^{2}=.03, r=.55$, Power $=.67$} \\
\hline & \multicolumn{2}{|c|}{ Listeria } & & & \multicolumn{2}{|c|}{ Digital Eye Strain } & & \\
\hline & $\begin{array}{l}\text { High } \\
\text { efficacy }\end{array}$ & $\begin{array}{l}\text { Low } \\
\text { efficacy }\end{array}$ & $F$ & $p$ & High efficacy & $\begin{array}{l}\text { Low } \\
\text { efficacy }\end{array}$ & $F$ & $p$ \\
\hline Threat & & & 0.25 & .61 & & & 0.20 & .65 \\
\hline Efficacy & 5.86 & 4.89 & 42.10 & $<.001$ & 5.92 & 4.90 & 67.48 & $<.001$ \\
\hline Threat*Efficacy & & & 3.56 & .06 & & & 0.54 & .46 \\
\hline \multicolumn{5}{|c|}{$\eta^{2}=.17, r=.41$ Power $=1.0$} & \multicolumn{4}{|c|}{$\eta^{2}=.24, r=.49$ Power $=1.0$} \\
\hline
\end{tabular}

First, the main and interactive effects of threat and efficacy manipulations on intention to follow the recommendation and intention to share were tested using a mixed effects model. Message topic was treated as a repeated factor while the manipulations of threat and efficacy were entered as between-subject factors. The results suggested that message topic was neither a significant influencer on participants' intention to follow the message $(F(1,210)=3.73, p=.06)$ nor 
on participants' intention to share the message $(F(1,210)=1.63, p=.81)$. No significant interaction effect was observed with message topic and threat and efficacy on dependent variables either. Therefore, the average value of two sets of responses for intention to follow and share the Listeria and Digital Eye Strain messages were taken and used in a moderated mediation model with a regression-based path analysis using PROCESS (Hayes, 2018; Preacher et al., 2006; Preacher et al., 2007) in SPSS version 23.0. Three moderated mediation models were tested with PROCESS (Model \#7). The manipulation of threat, the manipulation of efficacy and fear was entered as IV or a covariate in the first, second and third model respectively. In this way, the PROCESS models allowed for simultaneous examination of the influence of message-level attributes (threat and efficacy message manipulations), fear, the intention to follow the message, individuals' information process style, and image promotion's influence on their intention to share the fear appeal messages.

PROCESS generates bias-corrected and accelerated $95 \%$ confidence intervals (CI) based on 10,000 bootstrap samples to test mediation (Hayes, 2018). When either the lower and upper $95 \% \mathrm{Cls}$ are both below or above zero, the statistically significant mediation effects are supported. The mediation and moderation process analysis required the data to meet the standard assumptions of OLS regression in terms of normality, independence and homoscedasticity (Hayes, 2018). Therefore, the analysis began with an examination of the variables' correlations. No bivariate correlations were observed between inappropriate variables. Variance inflation factor (VIF) and tolerance results were also examined for other undesirable relationships between variables. The highest VIF was 1.36 while the tolerance, which is the reciprocal of VIF, was .74. Neither was worthy of concern (Hinton et al., 2004).

$\mathrm{H} 1$ and $\mathrm{H} 2$ proposed that high threat and high efficacy led to higher intention to share. In the second step of regression analyses as shown by Table 3, 4 and 5, high threat message significantly elevated participants' intention to share the fear appeal message $(B=0.41, p<.05)$. However, efficacy $(B=-0.11, p=.58)$ was not observed as having significant direct effect on intention to share. Therefore, $\mathrm{H} 1$ was supported, $\mathrm{H} 2$ was not supported.

Table 3. Ordinary Least Squares (OLS) Regression Coefficients (Model 1: Threat Manipulation as IV, $N=214$ ).

\begin{tabular}{|c|c|c|c|c|}
\hline \multirow{2}{*}{$\frac{\text { DV }}{\text { IV }}$} & \multicolumn{2}{|c|}{$\begin{array}{c}\text { Step } 1 \\
\text { Intention to follow the message }\end{array}$} & \multicolumn{2}{|c|}{$\begin{array}{c}\text { Step } 2 \\
\text { Intention to share } \\
\end{array}$} \\
\hline & $B(S E)$ & $p$ & $B(S E)$ & $p$ \\
\hline Constant & $-2.01(1.78)$ & .26 & $-2.60(1.70)$ & $<.01$ \\
\hline Age & $0.01(0.008)$ & .12 & $0.006(0.008)$ & .47 \\
\hline Gender & $0.31(0.20)$ & .13 & $0.03(0.20)$ & .89 \\
\hline Facebook use & $0.14(0.07)$ & $<.05$ & $0.18(0.07)$ & $<.01$ \\
\hline Health condition & $-0.02(0.11)$ & .84 & $0.10(0.11)$ & .36 \\
\hline Threat manipulation & $1.09(1.07)$ & .30 & $0.41(0.19)(1.04)$ & $<.05$ \\
\hline Efficacy manipulation & $0.56(0.20)$ & $<.01$ & $-0.11(0.19)$ & .58 \\
\hline Information processing & $0.98(0.33)$ & $<.01$ & - & - \\
\hline $\begin{array}{l}\text { Interaction of threat } \& \\
\text { processing }\end{array}$ & $-0.16(0.21)$ & .45 & - & - \\
\hline Image management concern & $0.27(0.07)$ & $<.001$ & $0.30(0.07)$ & $<.001$ \\
\hline Fear & $0.08(0.08)$ & .29 & $0.19(0.07)$ & $<.05$ \\
\hline $\begin{array}{l}\text { Intention to follow the } \\
\text { message }\end{array}$ & - & - & $0.49(0.06)$ & $<.001$ \\
\hline Model $\mathrm{R}^{2}$ & $.33(1.98)$ & $<.001$ & $.45(1.88)$ & $<.001$ \\
\hline $\begin{array}{l}\text { Conditional Indirect effect on } \\
\text { share }\end{array}$ & Information processing & Effect & BootLLCI & BootULCI \\
\hline Low & 4.13 & .22 & -.05 & .49 \\
\hline Medium & 5.08 & .14 & -.05 & .34 \\
\hline High & 6.03 & .07 & -.20 & .35 \\
\hline
\end{tabular}

Note. Unstandardized regression coefficients are reported. Variables were mean-centered prior to computing the interaction terms. 


\begin{tabular}{|c|c|c|c|c|}
\hline \multirow{2}{*}{$\begin{array}{l}\text { DV } \\
\text { IV }\end{array}$} & \multicolumn{2}{|c|}{$\begin{array}{c}\text { Step } 1 \\
\text { Intention to follow the message }\end{array}$} & \multicolumn{2}{|c|}{$\begin{array}{c}\text { Step } 2 \\
\text { Intention to share }\end{array}$} \\
\hline & $B(S E)$ & $p$ & $B(S E)$ & $p$ \\
\hline Constant & $-3.14(1.91)$ & .10 & $-2.60(0.80)$ & $<.001$ \\
\hline Age & $0.01(0.008)$ & .10 & $0.006(0.008)$ & .47 \\
\hline Gender & $0.29(0.20)$ & .15 & $0.03(0.20)$ & .89 \\
\hline Facebook use & $0.14(0.07)$ & $<.05$ & $0.18(0.07)$ & $<.01$ \\
\hline Health condition & $-0.02(0.11)$ & .88 & $0.10(0.11)$ & .36 \\
\hline Efficacy manipulation & $-0.91(1.08)$ & .40 & $-0.11(0.19)$ & .58 \\
\hline Threat manipulation & $0.27(0.20)$ & .16 & $0.41(0.19)$ & $<.05$ \\
\hline Information processing & $0.24(0.34)$ & .33 & - & - \\
\hline $\begin{array}{l}\text { Interaction of efficacy } \& \\
\text { processing }\end{array}$ & $0.29(0.21)$ & .18 & - & - \\
\hline Image & $0.27(0.07)$ & .16 & $0.30(0.07)$ & $<.001$ \\
\hline Fear & $0.10(0.08)$ & .20 & $0.19(0.07)$ & $<.05$ \\
\hline $\begin{array}{l}\text { Intention to follow the } \\
\text { message }\end{array}$ & - & - & $0.49(0.06)$ & $<.001$ \\
\hline Model $\mathrm{R}^{2}$ & .33 (1.96) & $<.001$ & $.45(1.88)$ & $<.001$ \\
\hline $\begin{array}{l}\text { Conditional Indirect effect } \\
\text { on share }\end{array}$ & $\begin{array}{l}\text { Information } \\
\text { processing }\end{array}$ & Effect & BootLLCI & BootULCI \\
\hline Low & 4.13 & .13 & -.14 & .41 \\
\hline Medium & 5.08 & .27 & .08 & .47 \\
\hline High & 6.03 & .40 & .13 & .70 \\
\hline
\end{tabular}

Note. Unstandardized regression coefficients are reported. Variables were mean-centered prior to computing the interaction terms.

Table 5. Ordinary Least Squares (OLS) Regression Coefficients (Model3: Fear as IV, $N=214$ ).

\begin{tabular}{|c|c|c|c|c|}
\hline \multirow{2}{*}{$\begin{array}{l}\text { DV } \\
\text { IV }\end{array}$} & \multicolumn{2}{|c|}{$\begin{array}{c}\text { Step } 1 \\
\text { Intention to follow the message }\end{array}$} & \multicolumn{2}{|c|}{$\begin{array}{c}\text { Step } 2 \\
\text { Intention to share }\end{array}$} \\
\hline & $B(S E)$ & $p$ & $B(S E)$ & $p$ \\
\hline Constant & 3.89 (1.91) & .003 & $-2.28(0.83)$ & $<.01$ \\
\hline Age & $0.01(0.008)$ & .10 & $0.006(0.008)$ & .47 \\
\hline Gender & $0.30(0.20)$ & .14 & $0.03(0.20)$ & .89 \\
\hline Facebook use & $0.15(0.07)$ & $<.05$ & $0.18(0.07)$ & $<.01$ \\
\hline Health condition & $-0.01(0.11)$ & .91 & $0.10(0.11)$ & .36 \\
\hline Efficacy manipulation & $0.50(0.20)$ & $<.05$ & $-0.11(0.19)$ & .58 \\
\hline Threat manipulation & $0.27(0.20)$ & .17 & $0.41(0.19)$ & $<.05$ \\
\hline Information processing & $0.94(0.21)$ & $<.001$ & - & - \\
\hline $\begin{array}{l}\text { Interaction of fear } \& \\
\text { processing }\end{array}$ & $-0.13(0.08)$ & .12 & - & - \\
\hline Image & $0.24(0.07)$ & $<.001$ & $0.30(0.07)$ & $<.001$ \\
\hline Fear & $0.78(0.44)$ & .08 & $0.19(0.07)$ & $<.05$ \\
\hline $\begin{array}{l}\text { Intention to follow the } \\
\text { message }\end{array}$ & - & - & $0.49(0.06)$ & $<.001$ \\
\hline Model $\mathrm{R}^{2}$ & $.34(1.96)$ & $<.001$ & .45 & $<.001$ \\
\hline $\begin{array}{l}\text { Conditional Indirect effect } \\
\text { on share }\end{array}$ & $\begin{array}{l}\text { Information } \\
\text { processing }\end{array}$ & Effect & BootLLCI & BootULCI \\
\hline Low & 4.13 & .13 & -.002 & .24 \\
\hline Medium & 5.08 & .27 & -.02 & .14 \\
\hline High & 6.03 & .40 & -.10 & .11 \\
\hline
\end{tabular}

Note. Unstandardized regression coefficients are reported. Variables were mean-centered prior to computing the interaction terms. 
H3 suggested fear as a positive predictor of intention to share. As shown in Table 3, 4, and 5, fear was found to be a significant positive predictor of intention to share $(B=0.19, p<.05)$, hence $\mathrm{H} 3$ was supported.

RQ1a, $1 \mathrm{~b}$ and 1c investigated the moderating effect of information processing on threat, efficacy and fear's influence on intention to follow the advised message. As Table 3, Table 4 and Table 5 demonstrated, no significant interaction effect was observed between information processing and threat, efficacy or fear on intention to follow the advice. Therefore, the answer to RQ1a, RQ1b and RQ1c was negative.

$\mathrm{H} 4 \mathrm{a}, 4 \mathrm{~b}$ and $4 \mathrm{c}$ hypothesized intention to follow the health advice mediates the moderated influence of threat, efficacy and fear by information processing on intention to share. While the moderated mediation paths were not observed to be significant with threat or fear, it was significant with efficacy on intention to share. As shown in Table 4, the mediated path was not significant when information processing level was low $(B=0.13,95 \% \mathrm{Cl}[-0.14,0.41]$, however, it became significant when information processing level was medium $(B=0.27,95 \% \mathrm{Cl}[0.08,0.47]$, and high $(B=0.40,95 \% \mathrm{Cl}[0.13$, $0.70])$. Therefore, $\mathrm{H} 4 \mathrm{a}, 4 \mathrm{c}$ were not supported. $\mathrm{H} 4 \mathrm{~b}$ was supported.

$\mathrm{H} 5$ proposed that individual's desire for image promotion was positively associated with their intention to share. As indicated in Table 3, 4 and 5, image concern was a significant positive predictor of sharing intention $(B=0.30, p<.001)$. Therefore, $\mathrm{H} 5$ was supported.

Obvious, some variables are significant while some are not. For clarity purposes, all significant effects were presented in Figure 2.

Figure 2. Significant Factors Predicting Intention to Share.

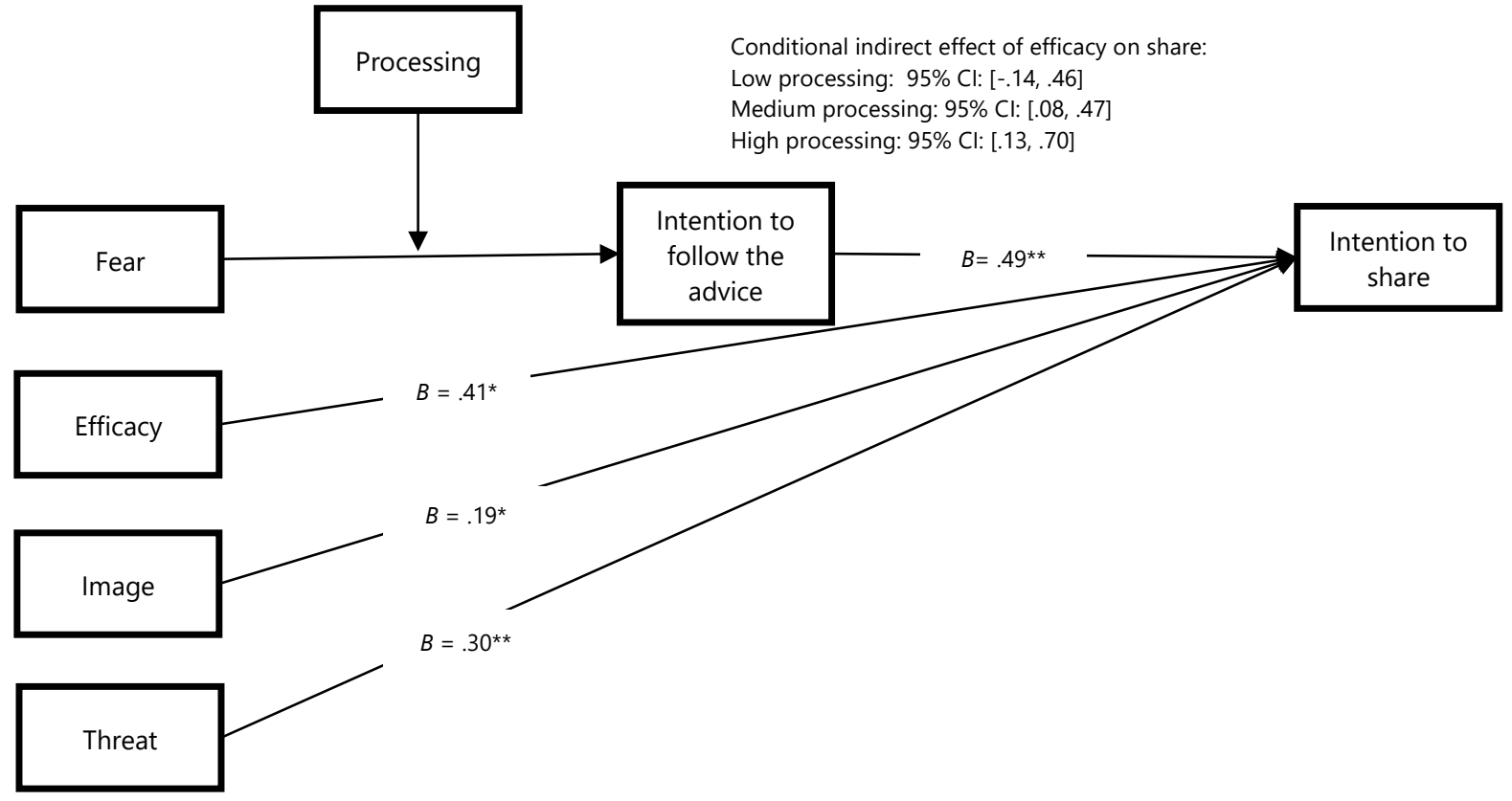

\section{Discussion}

Sharing is key in disseminating health information on social media. This study took into consideration both health content features manifested by threat and efficacy, fear, as well as user variables, including processing style and image concern, in an attempt to look at sharing behaviors of such messages in a new context. Overall, our results documented direct effect of threat, fear, and image promotion consideration, and indirect effect of efficacy in motivating intention to share fear appeal health messages on SNS. These results (as shown in Table 6) painted a rather intricate picture of contributing variables to share, hence, extended the fear appeal studies into a context of information dissemination on SNS. 
Table 6. Hypotheses Testing and Answers to Research Question.

\begin{tabular}{ll}
\hline Hypotheses/Research Questions & Results \\
\hline H1: A high threat message elicits higher intention to share on social media as & Supported \\
compared to a low threat message. & \\
H2: A high efficacy message elicits higher intention to share on social media as & Not supported \\
compared to a low efficacy message. & \\
H3: Fear is positively related to users' intention to share on social media. & Supported \\
RQ1a: Does information processing moderate threat in influencing intention to & Negative \\
follow the advised message? & \\
RQ1b: Does information processing moderate efficacy in influencing intention & Negative \\
to follow the advised message? & \\
RQ1c: Does information processing moderate fear in influencing intention to & Negative \\
follow the advised message? & \\
H4a: Intention to follow the advice mediates the moderated effect of threat by & Not supported \\
information processing on users' intention to share fear appeal messages on & \\
SNS & \\
H4b: Intention to follow the advice mediates the moderated effect of efficacy by & Partially supported \\
information processing on users' intention to share fear appeal message on SNS & \\
H4c: Intention to follow the advice mediates the moderated effect of fear on & Not supported \\
users' intention to share fear appeal messages on SNS & \\
H5: Willingness to create a positive image of oneself on Facebook positively & Supported \\
predicts intention to share the fear appeal message. & \\
\hline
\end{tabular}

To start with, the results showed participants' intention to share was significantly and directly predicted by threat condition $(B=0.41, p<.05)$ and level of fear $(B=0.19, p<.05)$. Unlike efficacy, threat and fear's influence on intention to share was not mediated by intention to follow the advice. It suggests that the emergency and importance of health risks do not need to trigger information processing to motivate sharing. Users also do not need to perceive information as beneficial when they are scared to share it on social media. Previous studies in health risk communication posit that health crisis tends to create a volatile communication environment (Glik, 2007). People then often misperceive probabilities and seriousness and have difficulties understanding cumulative risks. In this circumstance, it is very possible that the participants intend to share risk messages because they need to release fear immediately, limiting time to form cognitive evaluation of the message. This proposition seems to be supported by the absence effect of information processing, as it suggests that while participants intend to share a health risk message because of threat and fear, they don't need to be engaged with a particular type of information processing. Future study should continue to explore what kind of message design is more effective in engaging SNS users in systematic processing that enhances persuasion and further the chance that the message getting disseminated on social media.

On the other hand, as fear in the current study was seen as below the median point of the scale $(M=2.29, S D=1.34)$, such results seem to support the claim that fear serves as an emotional drive for protective action when it is moderate (Janis, 1967; McGuire, 1968, 1969). It is possible that in the current study fear was just sufficient to drive behavioral intention and yet not too high to trigger defensive psychological mechanism (e.g., Ruiter et al., 2014). Future research could continue to define the range of fear that could be perceived as effective in motivating behavioral and sharing intentions.

Unlike threat and fear, the influence of efficacy on intention to share was moderated by information processing and mediated by intention to follow the advice. A different psychological mechanism is indicated here underlying the motivational effect of efficacy compared with what underlies threat and fear. When participants indicate sharing intention because of threat and fear they may not necessarily agree with the message. However, when they intend to share because of the efficacy message, they indicate at the same time that they have been solidly persuaded and agree with the message they'd like to let their Facebook friend(s) know. From the perspective of informational utility (Knobloch et al., 2003), the significant effect of efficacy on intention to share seems to suggest that higher efficacy perception is associated with higher perceived utility of the fear appeal messages. Although Knobloch et al. (2003) conceptualize informational utility as a multi-dimension construct that considers the magnitude, likelihood, and perceived immediacy or proximity of an issue, it is possible that these dimensions weigh differently in predicting informational utility when it comes to different types of information. The current results seem to suggest that when it comes to health risk issues, 
efficacy is a more important element of utility. Future studies should continue to examine the concept of perceived utility and its' multiple dimensions' role in various communication scenarios.

At a time when the Internet is plagued with misinformation and Facebook has become a battlefield fighting fake news, every SNS user could contribute to spreading misinformation. The question is do users realize they are spreading misinformation, or believe in the message they spread out? Our results suggest that it depends on why users share. Dual-processing theories (Eagly \& Chaiken, 1993; Petty \& Cacioppo, 1986) suggest that people who systematically process the information about a given topic tend to develop stable attitude toward the topic, whereas heuristic processors are more likely to develop superficial understandings. The results of the current study suggest people can be driven to share with or without information processing effort. When the participants share because of threat and fear, they may not necessarily scrutinize the fear appeal message to decide its value. However, when they intend to share because of the efficacy message, sharing intention is indeed associated with the sharer's intention to follow the message and is moderated by information processing. This result is consistent with Shi et al. (2018)'s findings that suggest factors both on the central and peripheral processing route can trigger retweeting decisions. Identifying the influence of information processing on intention to share will help health communicators target a relevant and caring audience on a specific health issue, therefore, future studies should continue to examine the influence of information processing on sharing.

Another important finding relates to the positive effect of users' concerns for promoting their images on social media. Our results suggest when participants believe sharing fear appeal messages would make them look better on social media, they report higher intentions to share. Previous studies propose social media activity is motivated by individuals' need for self-enhancement and to appear more likeable (Lee et al., 2012). Our results suggest that sharing fear appeal information is no exception. The detected relationship between image promotion concern and intention to share may fulfill a purpose of self-esteem enhancement. Examining the mediating variable between self-esteem, image management concern, and intentions to share would be a worthwhile direction for future research.

The findings of this study have important implications for health communicators. First, although intention to share can be a pure reaction toward threat and fear, message designers should still recognize the importance of persuasion that could also motivate share. More importantly, as the motivating effect of persuasion is a function of elevated efficacy and systematic processing, this mediated path represents a more dedicated effort of self-protection. Providing truly useful information to SNS users not only helps to maximize dissemination, but also enhances the effectiveness of health risk communication.

On the other hand, health communicators should realize the direct effect of threat and fear on share is a double-edge sword. Threat and fear had an immediate motivating effect on intention to share, so message designers may consider including more emotional cues, such as pictures to arouse fear in order to motivate information dissemination on social media platforms. However, when dissemination is boosted with emotional cues, communicators should also be aware that users pass along the message without going through an analytical or deliberative reasoning styles for processing fear appeal information. In order to get valid and reliable message passed along, consideration should be given to precise and effective reasoning strategies that can be used by the vulnerable population.

As image-promotion is detected as a predictor of intention to share, health communicators should try to reduce sensitive content that might hurt image if the aim is to get the risk message shared publicly, while providing positive information that may benefit people's image to encourage share. While the judgment of what message elements would promote images is rather subjective, there have never been so many opportunities for one to tailor social media content at an individual level than before. Today's social media already feed advertisements based on users' purchasing history. Similar computer algorithm could also be applied to analyze the content social media users share to better understand their image consideration. It is hoped that by providing health message that has potentials to promote one's image will promote share. On the other hand, the health-related content shared by social media users can also be tracked and analyzed to detect potential issues individual users may perceive threatening and the advice perceived to be useful. Feeding health message using fear appeal that matches individual users' interests will potentially promote systematic processing and enable more effective dissemination. 


\section{Study Limitations and Conclusion}

This study is limited by several methodology issues. First, the measurement of several variables needs to be improved to capture their real relationships. For example, fear, as an emotional response is automatic and preconscious and may not be precisely reflected with Likert-type scale reports. As suggested by previous scholars (Ruiter, Abraham et al., 2001), psychophysiological measures, such as the galvanic skin response or the startle reflex, might better determine levels of fear. Similarly, share was measured as intentions, which in the real life might just be spontaneous decisions. The experiment design could be improved by testing more health topics with one model, or developing a unique model to predict social media users' intention to forward a particular health risk. The MTurk is an effective platform to recruit a sample of diverse demographic features; however, our respondents do not perfectly mirror the wider world. Therefore, care should be taken in generalizing the current results to a boarder population. Future studies will benefit by testing the results using samples recruited with different methods. Future research could also improve on similar projects by addressing not only the issues mentioned above, but a number of other areas as well. As previous studies have suggested a wide variety of uses and gratifications, such as information seeking, socializing, entertainment, status seeking, social influence, attention seeking, habitual past of time can be related to news sharing (Lee \& Ma, 2012) and photo sharing on social media (Malik et al., 2015), these factors also have the potential to influence message sharing on social media. Examining potential moderation effect of different motives of sharing on the threat, efficacy and fear on driving sharing of health message will provide a more nuanced analysis of social media users' experience with health message, generating opportunities for theory development. The context of the study can go beyond Facebook as today's social media are updating themselves by creating more and more functions and tools.

\section{References}

Adzharuddin, N. A., \& Ramly, N. M. (2015). Nourishing healthcare information over Facebook. Procedia - Social and Behavioral Sciences, 172, 383-389. https://doi.org/10.1016/j.sbspro.2015.01.384

Allport, G. W., \& Postman, L. (1947). The psychology of rumor. Henry Holt.

Averbeck, J. M., Jones, A., \& Robertson, K. (2011). Prior knowledge and health messages: An examination of affect as heuristics and information as systematic processing for fear appeals. Southern Communication Journal, 76(1), 35-54. https://doi.org/10.1080/10417940902951824

Bandura, A. (1996). Self-efficacy: The exercise of control. Freeman.

Baym, N. K. (2010). Personal connections in the digital age. Polity.

Berger, J. (2011). Arousal increases social transmission of information. Psychological Science, 22(7), 891-893.

https://doi.org/10.1177/0956797611413294

Berger, J., \& Milkman, K. L. (2012). What makes online content viral? Journal of Marketing Research, 49(2), 192-205. https://doi.org/10.1509/jmr.10.0353

Cameron, K. A., Wolf, M. S., \& Baker, D. W. (2011). Integrating health literacy in health communication. In T. L. Thompson, R. Parrott, \& J. F. Nussbaum (Eds.), The Routledge handbook of health communication (2nd. ed., pp. 306319). Routledge.

Centers for Disease Control and Prevention. (2015, August 12). Facebook guidelines and best practices. https://www.cdc.gov/socialmedia/tools/guidelines/facebook-guidelines.html

Chaiken, S., Liberman A., \& Eagly, A. H. (1989). Heuristic and systematic information processing within and beyond the information processing context. In J. S. Uleman \& J. A. Bargh (Eds.), Unintended thought (pp. 212-252). Guildford Press

Cho, H., Chen, M., \& Chung, S. (2010). Testing an integrative theoretical model of knowledge-sharing behavior in the context of Wikipedia. Journal of the American Society for Information Science and Technology, 61(6), 1198-1212.

https://doi.org/10.1002/asi.21316 
De Choudhury, M., Ringel Morris, M., \& White, R. W. (2014). Seeking and sharing health information online: comparing search engines and social media. In CHI '14: Proceedings of the SIGCHI Conference on Human Factors in Computing Systems (pp. 1365-1376). ACM. https://doi.org/10.1145/2556288.2557214

de Hoog, N., Stroebe, W., \& de Wit, J. B. F. (2007). The impact of vulnerability to and severity of a health risk on processing and acceptance of fear-arousing communications: A meta-analysis. Review of General Psychology, 11(3), 258-285 https://doi.org/10.1037/1089-2680.11.3.258

de Hoog, N., Stroebe, W., \& de Wit, J. B. F. (2008). The processing of fear-arousing communications: How biased processing leads to persuasion. Social Influence, 3(2), 84-113. https://doi.org/10.1080/15534510802185836

Dillman Carpentier, F. R. (2008). Applicability of the informational utility model for radio news. Journalism \& Mass Communication Quarterly, 85(3), 577-590. https://doi.org/10.1177/107769900808500306

Eagly, A. H., \& Chaiken, S. (1993). The psychology of attitudes. Harcourt Brace Jovanovich College Publishers.

Ellison, N. B., Steinfield, C., \& Lampe, C. (2007). The benefits of Facebook "friends:" Social capital and college students' use of online social network sites. Journal of Computer-Mediated Communication, 12(4), 1143-1168.

https://doi.org/10.1111/j.1083-6101.2007.00367.x

Faul, F., Erdfelder, E., Lang, A.-G., \& Buchner, A. (2007). G* Power 3: A flexible statistical power analysis program for the social, behavioral, and biomedical sciences. Behavior Research Methods, 39(2), 175-191.

https://doi.org/10.3758/BF03193146

Floyd, D. L., Prentice-Dunn, S., \& Rogers, R. W. (2000). A meta-analysis of research on protection motivation theory. Journal of Applied Social Psychology, 30(2), 407-429. https://doi.org/10.1111/j.1559-1816.2000.tb02323.x

Gentile, B., Twenge, J. M., Freeman, E. C., \& Campbell, W. K. (2012). The effect of social networking websites on positive self-views: An experimental investigation. Computers in Human Behavior, 28(5), 1929-1933.

https://doi.org/10.1016/j.chb.2012.05.012

Gleicher, F., \& Petty, R. E. (1992). Expectations of reassurance influence the nature of fear-stimulated attitude change. Journal of Experimental Social Psychology, 28(1), 86-100. https://doi.org/10.1016/0022-1031(92)90033-G

Glik, D. C. (2007). Risk communication for public health emergencies. Annual Review of Public Health, 28, 33-54.

https://doi.org/10.1146/annurev.publhealth.28.021406.144123

Gonzales, A. L., \& Hancock, J. T. (2011). Mirror, mirror on my Facebook wall: Effects of exposure to Facebook on selfesteem. Cyberpsychology, Behavior, and Social Networking, 14(1-2), 79-83. https://doi.org/10.1089/cyber.2009.0411

Greenwood, S., Perrin, A., \& Duggan, M. (2016, November 11). Social media update 2016. Pew Research Center: Internet \& Technology. http://www.pewinternet.org/2016/11/11/social-media-update-2016/

Gretzel, U., \& Yoo, K. H. (2008). Use and impact of online travel reviews. In P. O'Connor, W. Höpken, \& U. Gretzel (Eds.), Information and communication technologies in tourism 2008 (pp. 35-46). Springer.

Griffin, R. J., Dunwoody, S., \& Neuwirth, K. (1999). Proposed model of the relationship of risk information seeking and processing to the development of preventive behaviors. Environmental Research, 80(2), S230-S245.

https://doi.org/10.1006/enrs.1998.3940

Hansen, J., Winzeler, S., \& Topolinski, S. (2010). When the death makes you smoke: A terror management perspective on the effectiveness of cigarette on-pack warnings. Journal of Experimental Social Psychology, 46(1), 226-228.

https://doi.org/10.1016/j.jesp.2009.09.007

Harris, A. L., \& Rea, A. (2009). Web 2.0 and virtual world technologies: A growing impact on IS education. Journal of Information Systems Education, 20(2), 137-144. 
Hayes, A. F. (2018). Introduction to mediation, moderation, and conditional process analysis: A regression-based approach (2nd ed.). Guilford.

Hinton, P. R., McMurray, I., \& Brownlow, C. (2004). SPSS explained. Routledge.

Hovland, C. I., Janis, I. L., \& Kelly, H. H. (1953). Persuasion and communication: Psychological studies of opinion change. Yale University Press.

Hsu, M.-H., Ju, T. L., Yen, C.-H., \& Chang, C.-M. (2007). Knowledge sharing behavior in virtual communities: The relationship between trust, self-efficacy, and outcome expectations. International Journal of Human-Computer Studies, 65(2), 153-169. https://doi.org/10.1016/j.ijhcs.2006.09.003

Hutchinson, A. (2019, April 24). Facebook reaches 2.38 billion users, beats revenue estimates in latest update. Social Media Today. https://www.socialmediatoday.com/news/facebook-reaches-238-billion-users-beats-revenue-estimatesin-latest-upda/553403/

Jacobs, W., Amuta, A. O., \& Jeon, K. C. (2017). Health information seeking in the digital age: An analysis of health information seeking behavior among US adults. Cogent Social Sciences, 3(1), Article 1302785.

https://doi.org/10.1080/23311886.2017.1302785

Janis, I. L. (1967). Effects of fear arousal on attitude change: Recent developments in theory and experimental research. Advances in Experimental Social Psychology, 3, 166-224. https://doi.org/10.1016/S0065-2601(08)60344-5

Kahlor, L., Dunwoody, S., Griffin, R. J., Neuwirth, K., \& Giese, J. (2003). Studying heuristic-systematic processing of risk communication. Risk Analysis: An International Journal, 23(2), 355-368. https://doi.org/10.1111/1539-6924.00314

Katz, E. (1959). Mass communications research and the study of popular culture: An editorial note on a possible future for this journal. Studies in Public Communication, 2, 1-6. https://repository.upenn.edu/asc_papers/165

Knobloch, S., Dillman Carpentier, F., \& Zillmann, D. (2003). Effects of salience dimensions of informational utility on selective exposure to online news. Journalism \& Mass Communication Quarterly, 80(1), 91-108.

https://doi.org/10.1177/107769900308000107

Knobloch-Westerwick, S., Dillman Carpentier, F., Blumhoff, A., \& Nickel, N. (2005). Selective exposure effects for positive and negative news: Testing the robustness of the informational utility model. Journalism \& Mass Communication Quarterly, 82(1), 181-195. https://doi.org/10.1177/107769900508200112

Knobloch-Westerwick, S., \& Kleinman, S. B. (2012). Preelection selective exposure: Confirmation bias versus informational utility. Communication Research, 39(2), 170-193. https://doi.org/10.1177/0093650211400597

Knobloch-Westerwick, S., Mothes, C., Johnson, B. K., Westerwick, A., \& Donsbach, W. (2015). Political online information searching in Germany and the United States: Confirmation bias, source credibility, and attitude impacts. Journal of Communication, 65(3), 489-511. https://doi.org/10.1111/jcom.12154

Korda, H., \& Itani, Z. (2013). Harnessing social media for health promotion and behavior change. Health Promotion Practice, 14(1), 15-23. https://doi.org/10.1177/1524839911405850

Krämer, N. C., \& Winter, S. (2008). Impression management 2.0: The relationship of self-esteem, extraversion, selfefficacy, and self-presentation within social networking sites. Journal of Media Psychology, 20(3), 106-116.

https://doi.org/10.1027/1864-1105.20.3.106

Lee, C. S., \& Ma, L. (2012). News sharing in social media: The effect of gratifications and prior experience. Computers in Human Behavior, 28(2), 331-339. https://doi.org/10.1016/j.chb.2011.10.002 
Lee, J.-E. R., Moore, D. C., Park, E.-A., \& Park, S. G. (2012). Who wants to be "friend-rich"? Social compensatory friending on Facebook and the moderating role of public self-consciousness. Computers in Human Behavior, 28(3), 1036-1043. https://doi.org/10.1016/j.chb.2012.01.006

Leventhal, H. (1970). Findings and theory in the study of fear communications. Advances in Experimental Social Psychology, 5, 119-186. https://doi.org/10.1016/S0065-2601(08)60091-X

Leventhal, H. (1971). Fear appeals and persuasion: the differentiation of a motivational construct. American Journal of Public Health, 61(6), 1208-1224. https://doi.org/10.2105/AJPH.61.6.1208

Lopes, L. L. (1991). The rhetoric of irrationality. Theory \& Psychology, 1(1), 65-82.

https://doi.org/10.1177/0959354391011005

Luminet IV, O., Bouts, P., Delie, F., Manstead, A. S. R., \& Rimé, B. (2000). Social sharing of emotion following exposure to a negatively valenced situation. Cognition \& Emotion, 14(5), 661-688. https://doi.org/10.1080/02699930050117666

Malik, A., Amandeep, D., \& Nieminen, M. (2015). Facebook photo tagging culture and practices among digital natives. In CCGIDIS 2015 - Fifth International Symposium on Communicability, Computer Graphics and Innovative Design for Interactive Systems. Blue Herons Editions.

Marwick, A. E. (2011). I tweet honestly, I tweet passionately: Twitter users, context collapse, and the imagined audience. New Media \& Society, 13(1), 114-133. https://doi.org/10.1177/1461444810365313

McGuire, W. J. (1968). Personality and attitude change: An information-processing theory. In A. G. Greenwald, T. C. Brock, \& T. M. Ostrom (Eds.), Psychological Foundations of Attitudes (pp. 171-196). Academic Press.

McGuire, W. J. (1969). The nature of attitudes and attitude change. In G. Lindzey \& E. Aronson (Eds.), The handbook of social psychology (2nd ed., Vol. 3, pp. 136-314). Addison-Wesley.

Milne, S., Sheeran, P., \& Orbell, S. (2000). Prediction and intervention in health-related behavior: A meta-analytic review of protection motivation theory. Journal of Applied Social Psychology, 30(1), 106-143. https://doi.org/10.1111/j.15591816.2000.tb02308.x

Munar, A. M., \& Ooi, C.-S. (2012). What social media tell us about the heritage experience. Copenhagen Business School.

Newman, M. W., Lauterbach, D., Munson, S. A., Resnick, P., \& Morris, M. E. (2011). It's not that I don't have problems, I'm just not putting them on Facebook: Challenges and opportunities in using online social networks for health. In Proceedings of the ACM 2011 Conference on Computer Supported Cooperative Work (pp. 341-350). ACM.

Oh, O., Kwon, K. H., \& Rao, H. R. (2010). An exploration of social media in extreme events: Rumor theory and Twitter during the Haiti earthquake 2010. In ICIS 2010 Proceedings - Thirty First International Conference on Information Systems.

Oh, S., \& Syn, S. Y. (2015). Motivations for sharing information and social support in social media: A comparative analysis of Facebook, Twitter, Delicious, YouTube, and Flickr. Journal of the Association for Information Science and Technology, 66(10), 2045-2060. https://doi.org/10.1002/asi.23320

O'Keefe, D. J. (2015). Message generalizations that support evidence-based persuasive message design: Specifying the evidentiary requirements. Health Communication, 30(2), 106-113. https://doi.org/10.1080/10410236.2014.974123

Petty, R. E., \& Cacioppo, J. T. (1986). The elaboration likelihood model of persuasion. In R. E. Petty \& J. T. Cacioppo (Eds.), Communication and persuasion: Central and peripheral routes to attitude change (pp. 1-24). Springer-Verlag.

Preacher, K. J., Curran, P. J., \& Bauer, D. J. (2006). Computational tools for probing interactions in multiple linear regression, multilevel modeling, and latent curve analysis. Journal of Educational and Behavioral Statistics, 31(4), 437448. https://doi.org/10.3102/10769986031004437 
Preacher, K. J., Rucker, D. D., \& Hayes, A. F. (2007). Addressing moderated mediation hypotheses: Theory, methods, and prescriptions. Multivariate Behavioral Research, 42(1), 185-227. https://doi.org/10.1080/00273170701341316

Rimal, R. N., \& Real, K. (2003). Perceived risk and efficacy beliefs as motivators of change. Human Communication Research, 29(3), 370-399. https://doi.org/10.1111/j.1468-2958.2003.tb00844.x

Rogers, R. W. (1983). Cognitive and physiological processes in fear appeals and attitude change: A revised theory of protection motivation. In J. T. Cacioppo \& R. E. Petty (Eds.), Social Psychophysiology (pp. 153-176). Guilford.

Rubin, A. M. (2009). Uses-and-gratifications perspective on media effects. In J. Bryant \& M. B. Oliver (Eds.), Media effects: Advances in Theory and Research (3rd ed., pp. 181-200). Routledge.

Ruiter, P.A., Kessels, L.T., Peters, G. J. Y., \& Kok, G. (2014). Sixty years of fear appeal research: Current state of the evidence. International Journal of Psychology, 49(2), 63-70. https://doi.org/10.1002/ijop.12042

Ruiter, R. A. C., Kok, G., Verplanken, B., \& Brug, J. (2001). Evoked fear and effects of appeals on attitudes to performing breast self-examination: An information-processing perspective. Health Education Research, 16(3), 307-319.

https://doi.org/10.1093/her/16.3.307

Ruiter, R. A. C., Abraham, C., \& Kok, G. (2001). Scary warnings and rational precautions: A review of the psychology of fear appeals. Psychology \& Health, 16(6), 613-630. https://doi.org/10.1080/08870440108405863

Scanfeld, D., Scanfeld, V., \& Larson, E. L. (2010). Dissemination of health information through social networks: Twitter and antibiotics. American Journal of Infection Control, 38(3), 182-188. https://doi.org/10.1016/j.ajic.2009.11.004

Shi, J., Hu, P., Lai, K. K., \& Chen, G. (2018). Determinants of users' information dissemination behavior on social networking sites: An elaboration likelihood model perspective. Internet Research, 28(2), 393-418.

https://doi.org/10.1108/IntR-01-2017-0038

Stieglitz, S., \& Dang-Xuan, L. (2013). Emotions and information diffusion in social media-sentiment of microblogs and sharing behavior. Journal of Management Information Systems, 29(4), 217-248. https://doi.org/10.2753/MIS0742-

1222290408

Tannenbaum, M. B., Hepler, J., Zimmerman, R. S., Saul, L., Jacobs, S., Wilson, K., \& Albarracín, D. (2015). Appealing to fear: A meta-analysis of fear appeal effectiveness and theories. Psychological Bulletin, 141(6), 1178-1204.

https://doi.org/10.1037/a0039729

Thackeray, R., Neiger, B. L., Hanson, C. L., \& McKenzie, J. F. (2008). Enhancing promotional strategies within social marketing programs: Use of Web 2.0 social media. Health Promotion Practice, 9(4), 338-343.

https://doi.org/10.1177/1524839908325335

Torabi, S., \& Beznosov, K. (2013, August 12). Privacy aspects of health related information sharing in online social networks [Paper presentation]. 2013 USENIX Workshop on Health Information Technologies.

https://www.usenix.org/conference/healthtech13/workshop-program/presentation/torabi

Trumbo, C. W. (2002). Information processing and risk perception: An adaptation of the heuristic-systematic model. Journal of Communication, 52(2), 367-382. https://doi.org/10.1111/j.1460-2466.2002.tb02550.x

Turel, O., \& Gil-Or, O. (2019). To share or not to share? The roles of false Facebook self, sex, and narcissism in reposting self-image enhancing products. Personality and Individual Differences, 151, Article 109506.

https://doi.org/10.1016/j.paid.2019.109506

Valkenburg, P. M., Schouten, A. P., \& Peter, J. (2005). Adolescents' identity experiments on the Internet. New Media \& Society, 7(3), 383-402. https://doi.org/10.1177/1461444805052282 
Witte, K. (1992). Putting the fear back into fear appeals: The extended parallel process model. Communications Monographs, 59(4), 329-349. https://doi.org/10.1080/03637759209376276

Witte, K., \& Allen, M. (2000). A meta-analysis of fear appeals: Implications for effective public health campaigns. Health Education \& Behavior, 27(5), 591-615. https://doi.org/10.1177/109019810002700506

Wojnicki, A. C., \& Godes, D. (2008). Word-of-mouth as self-enhancement (HBS Marketing Research Paper No. 06-01). http://dx.doi.org/10.2139/ssrn.908999

Woolley, P., \& Peterson, M. (2012). Efficacy of a health-related Facebook social network site on health-seeking behaviors. Social Marketing Quarterly, 18(1), 29-39. https://doi.org/10.1177/1524500411435481

Yang, Z. J., Aloe, A. M., \& Feeley, T. H. (2014). Risk information seeking and processing model: A meta-analysis. Journal of Communication, 64(1), 20-41. https://doi.org/10.1111/jcom.12071

Zhang, X., \& Zhou, S. (2019). Clicking health risk messages on social media: Moderated mediation paths through perceived threat, perceived efficacy, and fear arousal. Health Communication, 34(11), 1359-1368.

https://doi.org/10.1080/10410236.2018.1489202 


\section{Appendix A. Experiment Stimulus}

\section{Digital Eye Strain (High Threat/High Efficacy)}

\section{Staring At Digital Screens Can Mess With Vision}

70. CDC.JUST NOW A

Do you get the achy, tired feeling in your eyes that occurs after a stretch of screen viewing, leading to redness, tension, and even shoulder and head pain? CDC (Centers for Disease Control and Prevention) just published its 2016 report, finding that $\mathbf{9 3} \%$ of us are at risk for it - the digital eye strain. The report suggests that digital eye strain contributes to rising levels of myopia and in worse case, permanently affect retina, sclera, lens, cornea and cause permanent vision loss.

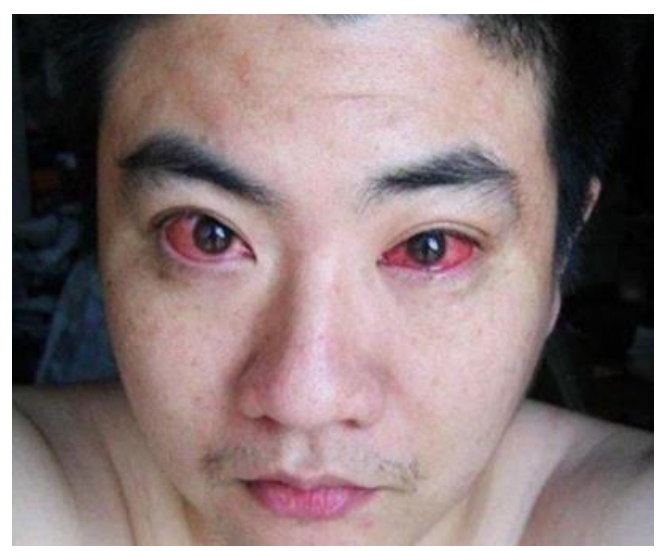

Unfortunately, CDC (Centers for Disease Control and Prevention)'s 2016 report found the average American (aged 1650) spends 7.4 hours staring at screens every day, almost as much as time we do sleeping. That explained why at least 1 out of every 3 eye patients complains about eye strain due to reading text on a digital screen. The eyes are strained because we blink less and squint to read on screens. The blue violet light emitted from the screen also put us at greater risk of macular degeneration, a leading cause of blindness. If you gaze at smartphone before falling asleep, the exposure to blue violet light also decrease levels of melatonin and make it harder to fall asleep and affect your moods. Cases have been seen that reading a smart phone with one eye leads to temporary blindness.

This is what CDC recommends to protect your eyes from screen strain:

1. Maintain a comfortable working distance at the computer (close to arm's length from the screen) and avoid hunching closer and closer.

2. When using a phone keep the screen as far away from your eyes as comfortably possible - the greater the distance your phone is from your eye, the less eye strain it is likely to cause.

3. Every 20 minutes, take a 20 -second break and look off into the distance - at something 20 feet away. This is called the "20-20-20 rule" by many eye care providers, and it relaxes the focusing muscle inside the eye, relaxes the muscles outside the eyes that converge the eyes, and stimulates blinking to remoisten the surface of the eyes - all comforting things! 
4. Ask your eye care provider about glasses that block blue light. There are a number of brands of eyeglass lenses and coatings that can reduce your exposure to HEV light when using digital devices.

5. Make sure your eyeglass lenses (if you need them) have an anti-reflective (AR) coating. Eliminating reflections from your lenses can increase viewing comfort and reduce eye strain.

6. Eat a diet rich in fruits and vegetables- particularly dark leafy greens such as spinach, kale, or collard greens. Research has also shown there are eye health benefits from eating fish high in omega- 3 fatty acids, such as salmon, tuna and halibut.

7. Go outside and play more!

Like Comment $\Rightarrow$ Share

Write a comment...

Press Enter to post.

Digital Eye Strain (High Threat/Low Efficacy)

\section{Staring At Digital Screens Can Mess With Vision}

CDC.JUST NOW \&

Do you get the achy, tired feeling in your eyes that occurs after a stretch of screen viewing, leading to redness, tension, and even shoulder and head pain? CDC (Centers for Disease Control and Prevention) just published its 2016 report, finding that $\mathbf{9 3} \%$ of us are at risk for it - the digital eye strain. The report suggests that digital eye strain contributes to rising levels of myopia and in worse case, permanently affect retina, sclera, lens, cornea and cause permanent vision loss.

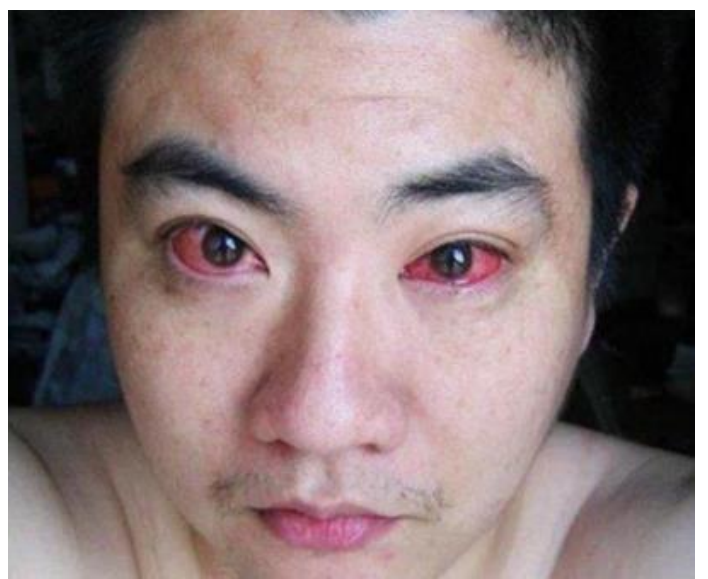

Unfortunately, CDC (Centers for Disease Control and Prevention)'s 2016 report found the average American (aged 1650) spends 7.4 hours staring at screens every day, almost as much as time we do sleeping. That explained why at least 1 out of every 3 eye patients complains about eye strain due to reading text on a digital screen. The eyes are strained because we blink less and squint to read on screens. The blue violet light emitted from the screen also put us at greater risk of macular degeneration, a leading cause of blindness. If you gaze at smartphone before falling asleep, 
the exposure to blue violet light also decrease levels of melatonin and make it harder to fall asleep and affect your moods. Cases have been seen that reading a smart phone with one eye leads to temporary blindness.

The best prevention against digital eye strain is to avoid staring at the screens. However, this method is not always very helpful for most people who work on computer every day. Some may have already been exposed to excessive blue violet light emitted from the screens and the harm that has been made to the back of the eyes is irreversible. Others may have developed myopia, which may put them at increased risk for digital eye strain. people with a family history of eye disease are even more vulnerable to digital eye strain. Some people recommend the eye exercises that make them feel as if they're doing something, taking a proactive step. However, there's no evidence that eye exercises prevent myopia or other harm that is done to eyes by blue violet light. Hopefully, we will find a cure to digital strain pretty soon. Until that happens, perhaps the best thing you can do is to take plenty of breaks from your laptop or mobile device to get out into the world, to balance close and distant focusing. Finding that kind of balance, in many areas of life, is the key to being healthy.

\begin{tabular}{l} 
It Like Comment $\Rightarrow$ Share \\
\hline Write a comment... \\
\hline Press Enter to post.
\end{tabular}

\section{Staring At Digital Screens Can Mess With Vision}

70 CDC.JUST NOW \&

Staring at screens for prolonged hours may result in redness, tension and even shoulder and head pain. However, CDC (Centers for Disease Control and Prevention)'s 2016 report of eye health finds only $\mathbf{5 \%}$ of us are at risk for the digital eye strain. It is suspected that staring at digital screens may cause nearsightedness only when staring at screens for more than $\mathbf{8}$ hours everyday. The report caution that although whether staring at a screen can change your vision is still controversial, reading at cellphone at bedtime can make it harder to fall asleep and affect moods.

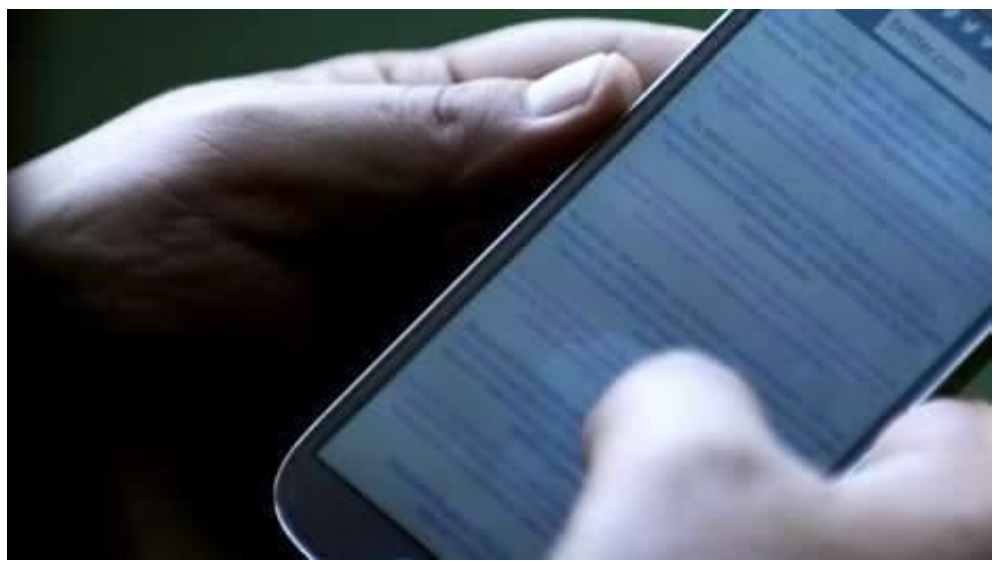

In their report, CDC found the average American (aged 16-50) spends 2.5 hours staring at screens every day, and 1 in 10 patients complains about eye strain due to reading text on a small screen. The eyes can be strained because we blink less and squint to read the miniature screens. So far researchers do not consider digital eye strain as a serious problem and noted that more studies need to be done before recognizing it as official medical condition. 
This is what $C D C$ recommends to protect your eyes from screen strain:

1. Maintain a comfortable working distance at the computer (close to arm's length from the screen) and avoid hunching closer and closer.

2. When using a phone keep the screen as far away from your eyes as comfortably possible - the greater the distance your phone is from your eye, the less eye strain it is likely to cause.

3. Every 20 minutes, take a 20 -second break and look off into the distance - at something 20 feet away. This is called the "20-20-20 rule" by many eye care providers, and it relaxes the focusing muscle inside the eye, relaxes the muscles outside the eyes that converge the eyes, and stimulates blinking to remoisten the surface of the eyes - all comforting things!

4. Ask your eye care provider about glasses that block blue light. There are a number of brands of eyeglass lenses and coatings that can reduce your exposure to HEV light when using digital devices.

5. Make sure your eyeglass lenses (if you need them) have an anti-reflective (AR) coating. Eliminating reflections from your lenses can increase viewing comfort and reduce eye strain.

6. Eat a diet rich in fruits and vegetables- particularly dark leafy greens such as spinach, kale, or collard greens. Research has also shown there are eye health benefits from eating fish high in omega- 3 fatty acids, such as salmon, tuna and halibut.

7. Go outside and play more!

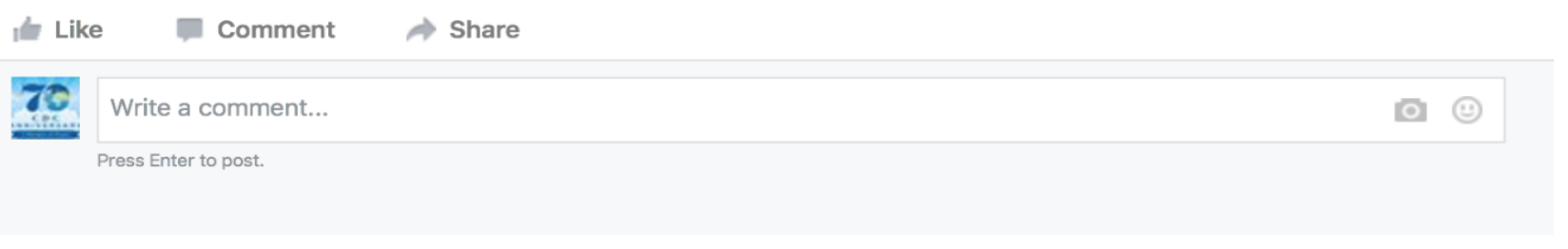

\section{Digital Eye Strain (Low Threat/High Efficacy)}

\section{Staring At Digital Screens Can Mess With Vision}

\section{CDC-JUST NOW is}

Staring at screens for prolonged hours may result in redness, tension and even shoulder and head pain. However, CDC (Centers for Disease Control and Prevention)'s 2016 report of eye health finds only 5\% of us are at risk for the digital eye strain. It is suspected that staring at digital screens may cause nearsightedness only when staring at screens for more than 8 hours everyday. The report caution that although whether staring at a screen can change your vision is still controversial, reading at cellphone at bedtime can make it harder to fall asleep and affect moods. 


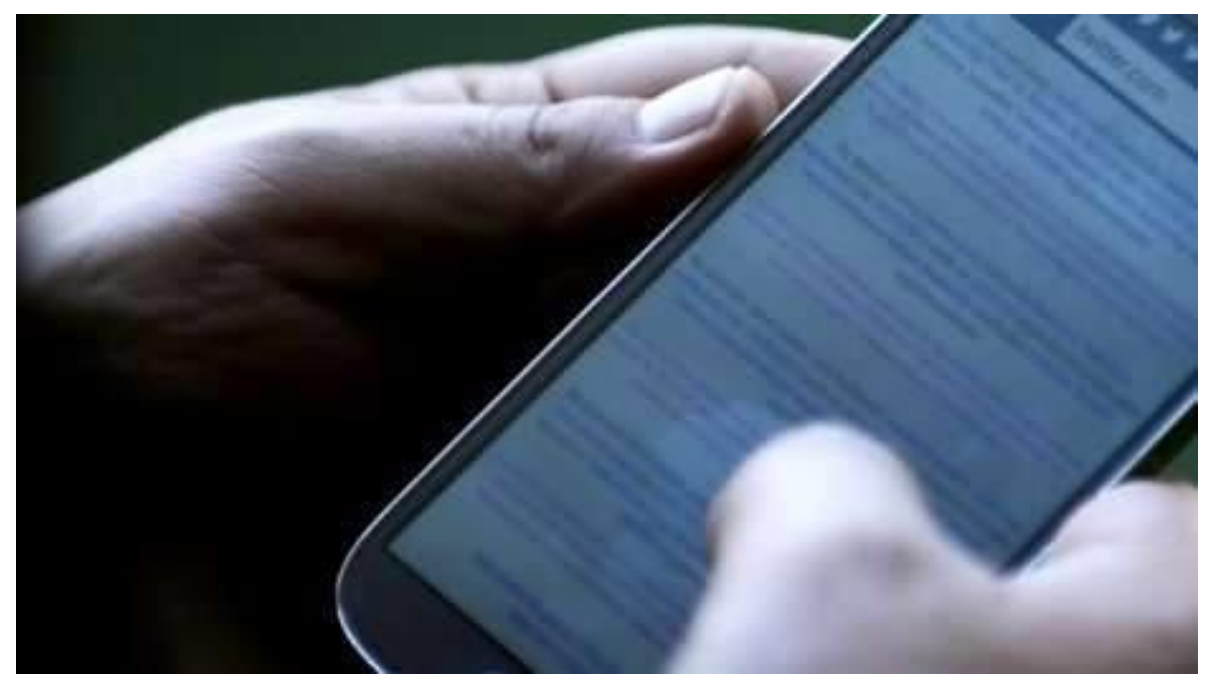

In their report, CDC found the average American (aged 16-50) spends 2.5 hours staring at screens every day, and 1 in 10 patients complains about eye strain due to reading text on a small screen. The eyes can be strained because we blink less and squint to read the miniature screens. So far researchers do not consider digital eye strain as a serious problem and noted that more studies need to be done before recognizing it as official medical condition.

The best prevention against digital eye strain is to avoid staring at the screens. However, this method is not always very helpful for most people who work on computer every day. Some may have already been exposed to excessive blue violet light emitted from the screens and the harm that has been made to the back of the eyes is irreversible. Others may have developed myopia, which may put them at increased risk for digital eye strain. people with a family history of eye disease are even more vulnerable to digital eye strain. Some people recommend the eye exercises that make them feel as if they're doing something, taking a proactive step. However, there's no evidence that eye exercises prevent myopia or other harm that is done to eyes by blue violet light. Hopefully, we will find a cure to digital strain pretty soon. Until that happens, perhaps the best thing you can do is to take plenty of breaks from your laptop or mobile device to get out into the world, to balance close and distant focusing. Finding that kind of balance, in many areas of life, is the key to being healthy.

In Like Comment $\Rightarrow$ Share

Write a comment...

Press Enter to post.

Listeria Outbreak (High Threat /High Efficacy)

\section{Multistate Outbreak of Listeria Linked to Packaged Salads Produced at Springfield, Ohio Dole Processing Facility}

70. CDC-JUST NOW \&

CDC is collaborating with public health officials in $\mathbf{2 3}$ states and the U.S. Food and Drug Administration (FDA) to investigate a multistate outbreak of Listeria monocytogenes infections (listeriosis). Listeria can cause a serious, life- 
threatening illness. A total of $\mathbf{5 0 0 0}$ people infected with the outbreak strain of Listeria were reported from $\mathbf{2 3}$ states, including $\mathbf{5 4}$ deaths. According to $C D C$, a person with Listeria usually has fever and muscle aches, sometimes preceded by diarrhea or other gastrointestinal symptoms. Infections during pregnancy can lead to miscarriage, stillbirth, premature delivery, or life-threatening infection of the newborn.

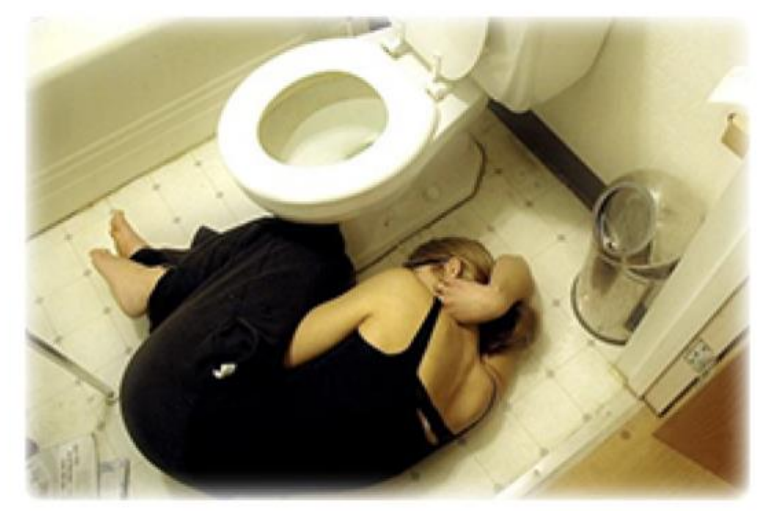

Epidemiological and laboratory evidence indicated that packaged salads produced at the Dole processing facility in Springfield, Ohio and sold under various brand names were the likely source of this outbreak. Dole Fresh Vegetables, Inc., is voluntarily withdrawing the salad mix with the following brand names: Dole, Fresh Selections, Simple Truth, Marketside, The Little Salad Bar and President's Choice Organics.

CDC experts said Listeria infection occurs often because of the improper way of handling food. If the following methods are followed, the chance of Listeria infection is very rare.

\section{CDC recommends:}

1. Wash food before eating

- Scrub firm produce, such as melons and cucumbers, with a clean produce brush.

- Separate uncooked meats and poultry from vegetables, cooked foods, and ready-to-eat foods.

2. Keep your kitchen and environment cleaner and safer.

- Wash hands, knives, countertops, and cutting boards after handling and preparing uncooked foods.

- Clean up all spills in your refrigerator right away-especially juices from hot dog and lunch meat packages, raw meat, and raw poultry.

3. Cook meat and poultry thoroughly

- Thoroughly cook raw food from animal sources, such as beef, pork, or poultry to a safe internal temperature. For a list of recommended temperatures for meat and poultry, visit the safe minimum cooking temperatures chart at FoodSafety.gov.

4. Store foods safely.

- Use precooked or ready-to-eat food as soon as you can. Do not store the product in the refrigerator beyond the use-by date; follow USDA refrigerator storage time guidelines:

- Hot Dogs - store opened package no longer than 1 week and unopened package no longer than 2 weeks in the refrigerator.

- Luncheon and Deli Meat - store factory-sealed, unopened package no longer than 2 weeks. Store opened packages and meat sliced at a local deli no longer than 3 to 5 days in the refrigerator.

5. Divide leftovers into shallow containers to promote rapid, even cooling. 


\title{
Multistate Outbreak of Listeria Linked to Packaged Salads Produced at Springfield, Ohio Dole Processing Facility
}

\author{
70 CDC-JUST NOW \&
}

CDC is collaborating with public health officials in 23 states and the U.S. Food and Drug Administration (FDA) to investigate a multistate outbreak of Listeria monocytogenes infections (listeriosis). Listeria can cause a serious, lifethreatening illness. A total of $\mathbf{5 3 4 1}$ people infected with the outbreak strain of Listeria were reported from $\mathbf{2 3}$ states, including 54 deaths. They ranged in age from 3 years to 83, with the medium age of 43 . According to CDC, a person with Listeria usually has fever and muscle aches, sometimes preceded by diarrhea or other gastrointestinal symptoms. Infections during pregnancy can lead to miscarriage, stillbirth, premature delivery, or life-threatening infection of the newborn.

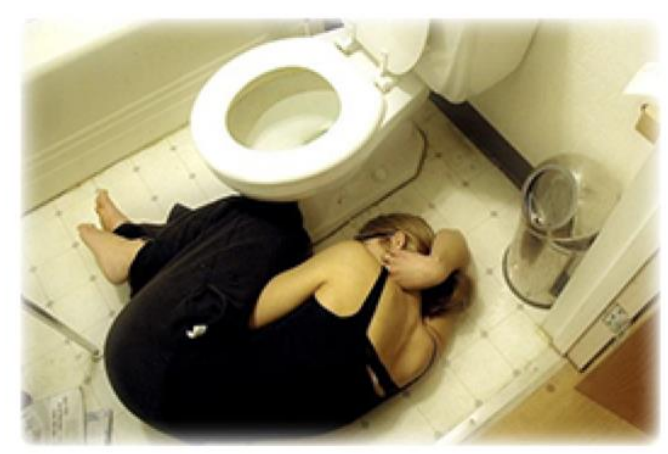

Epidemiologic and laboratory evidence indicated that packaged salads produced at the Dole processing facility in Springfield, Ohio and sold under various brand names were the likely source of this outbreak. CDC is still in the process of confirming brand names.

One of the reasons Listeria is so dangerous is its hardiness. Listeria can survive not only on refrigerated food, but also in and around the areas and utensils we use to cook as well as on the grocery shelves from which we select produce. It also thrives, of course, on uncooked foods like deli meats, seafood, cheese and other unpasteurized milk products. Add to this the fact that symptoms of infection might not occur for weeks after ingestion of the bacteria making it difficult to locate the source - and listeria becomes a serious problem.

Therefore, not consuming raw foods is recommended to reduce the risk of Listeria infection. Keeping your kitchen and environment cleaner and safer also helps. However, the infections starting from food industry are extremely hard to avoid. The recent recall of Dole packaged salads has just triggered a nation-wide discussion on how modern 
production methods and distribution networks can potentially turn a controllable, local issue into one that can cause problems nationwide.

$\underset{\text { Pike Comment } \Rightarrow \text { Share }}{7 \text { Write a comment... }}$

\section{Multistate Outbreak of Listeria Linked to Packaged Salads Produced at Springfield, Ohio Dole Processing Facility}

20 CDC-JUSTNOW 4

CDC is collaborating with public health officials and the U.S. Food and Drug Administration (FDA) to investigate a potential outbreak of Listeria monocytogenes infections (listeriosis). A total of $\mathbf{5}$ people infected with the outbreak strain of Listeria were reported from Ohio. Although ill people ranged in age from 3 years to 83, the medium age was 64 , meaning that older people are more likely to be infected. According to CDC expert, a person with Listeria usually has fever and muscle aches, sometimes preceded by diarrhea or other gastrointestinal symptoms. However, Listeria cases seldom result in death. Most listeria infection cases occur in high risk groups, such as older adults and people with other serious medical problems.

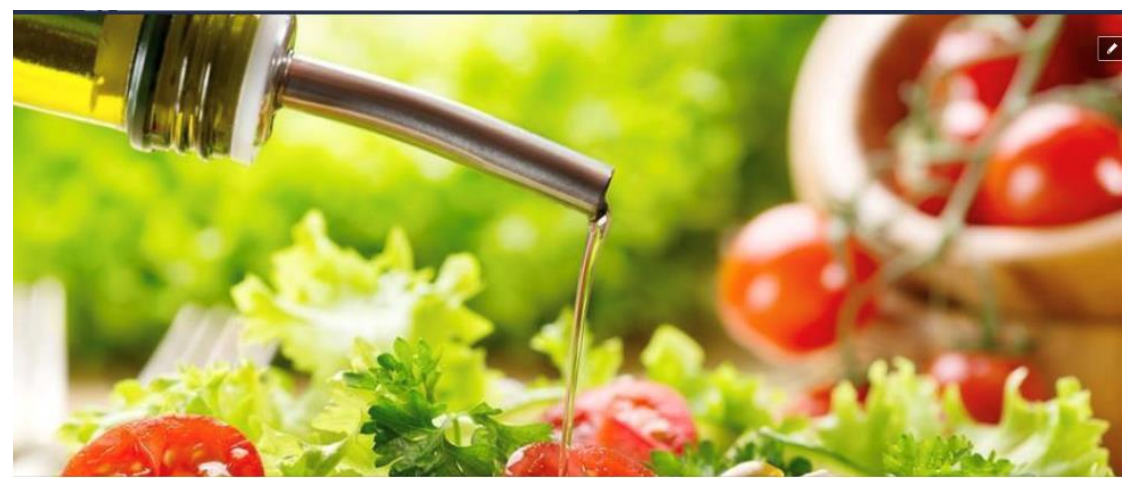

Epidemiological and laboratory evidence indicated that packaged salads produced at the Dole processing facility in Springfield, Ohio and sold under various brand names were the likely source of this outbreak. CDC is still in the process of confirming brand names. Dole Fresh Vegetables, Inc., has voluntarily withdrawn from the market all Dolebranded and private label packaged salads processed at that location.

CDC experts said Listeria infection occurs often because of improper ways of handling food. If the following methods are followed, the chance of Listeria infection is very rare.

CDC recommends:

1. Wash food before eating 
- Scrub firm produce, such as melons and cucumbers, with a clean produce brush.

- Separate uncooked meats and poultry from vegetables, cooked foods, and ready-to-eat foods.

2. Keep your kitchen and environment cleaner and safer.

- Wash hands, knives, countertops, and cutting boards after handling and preparing uncooked foods.

- Clean up all spills in your refrigerator right away-especially juices from hot dog and lunch meat packages, raw meat, and raw poultry.

3. Cook meat and poultry thoroughly

- Thoroughly cook raw food from animal sources, such as beef, pork, or poultry to a safe internal temperature.

- For a list of recommended temperatures for meat and poultry, visit the safe minimum cooking temperatures chart at FoodSafety.gov.

4. Store foods safely.

- Use precooked or ready-to-eat food as soon as you can.

- Do not store the product in the refrigerator beyond the use-by date; follow USDA refrigerator storage time guidelines: Hot Dogs - store opened package no longer than 1 week and unopened package no longer than 2 weeks in the refrigerator.

- Luncheon and Deli Meat - store factory-sealed, unopened package no longer than 2 weeks. Store opened packages and meat sliced at a local deli no longer than 3 to 5 days in the refrigerator.

5. Divide leftovers into shallow containers to promote rapid, even cooling.

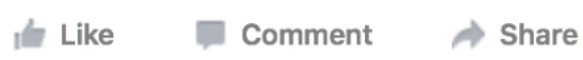

\section{Multistate Outbreak of Listeria Linked to Packaged Salads Produced at Springfield, Ohio Dole Processing Facility}

CDC-JUST NOW \&

CDC is collaborating with public health officials and the U.S. Food and Drug Administration (FDA) to investigate a potential outbreak of Listeria monocytogenes infections (listeriosis). A total of $\mathbf{5}$ people infected with the outbreak strain of Listeria were reported from Ohio. Although ill people ranged in age from 3 years to 83, the medium age was 64 , meaning that older people are more likely to be infected. According to CDC, a person with Listeria usually has fever and muscle aches, sometimes preceded by diarrhea or other gastrointestinal symptoms. However, Listeria cases seldom 
result in death. Most listeria infection cases occur in high risk groups, such as older adults and people with other serious medical problems.

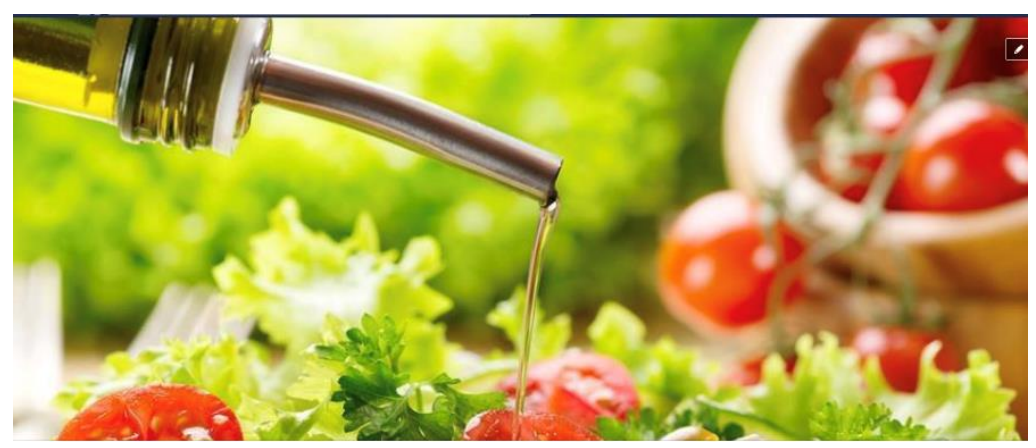

Epidemiologic and laboratory evidence indicated that packaged salads produced at the Dole processing facility in Springfield, Ohio and sold under various brand names were the likely source of this outbreak. CDC is still in the process of confirming brand names. Dole Fresh Vegetables, Inc., has voluntarily withdrawn from the market all Dole-branded and private label packaged salads processed at that location.

One of the reasons Listeria is so dangerous is its hardiness. Listeria can survive not only on refrigerated food, but also in and around the areas and utensils we use to cook as well as on the grocery shelves from which we select produce. It also thrives, of course, on uncooked foods like deli meats, seafood, cheese and other unpasteurized milk products. Add to this the fact that symptoms of infection might not occur for weeks after ingestion of the bacteria - making it difficult to locate the source - and listeria becomes a serious problem.

Therefore, not consuming raw foods is recommended to reduce the risk of Listeria infection. Keeping your kitchen and environment cleaner and safer also helps. However, the infections start from food industry are extremely to avoid. The recent recall of Dole packaged salads has just triggered a nation-wide discussion on how modern production methods and distribution networks can potentially turn a controllable, local issue into one that can cause problems nationwide.

It Like Comment $\Rightarrow$ Share 


\section{Correspondence to:}

Xueying Zhang

Department of Journalism and Mass Communication, North Carolina A\&T State University

1601 E Market St

Greensboro, NC 27411

United States

Email: xzhang2(at)ncat.edu

Editorial record: First submission received on September 21, 2019. Revisions received on February 8, 2020, March 5, 2020 and March 19, 2020. Accepted for publication on April 2, 2020.

Editor in charge: Lenka Dedkova

\section{About Authors}

Dr. Xueying Zhang is an assistant professor in the Department of Journalism and Mass Communication of North Carolina Agricultural and Technical State University. She conducts research on strategic health communication, examining how health-related perceptions, attitudes and behaviors can be changed through media use and persuasive communication.

Dr. Shuhua Zhou is Leonard H. Goldenson Professor of Radio \& Television at the School of Journalism, University of Missouri. His research focuses on media content, form and effects. Media psychology is his usual approach to cognitive processes of mediated communication. 